\title{
Introducing IEA EBC Annex 79: Key challenges and opportunities in the field of occupant-centric building design and operation
}

\begin{abstract}
Despite the fact that buildings are designed for occupants in principle, evidence suggests buildings are often uncomfortable compared to the requirements of standards; difficult to control by occupants; and, operated inefficiently with regards to occupants' preferences and presence. Meanwhile, practitioners architects, engineers, and building managers - lack the knowledge, tools, and precedent to design and operate buildings optimally considering the complex and diverse nature of occupants. Building on the success of IEA EBC Annex 66 ("Definition and simulation of occupant behavior in buildings"; 2013 2017), a follow-up IEA EBC Annex 79 (“Occupant-centric building design and operation”; 2018-2023) has been developed to address gaps in knowledge, practice, and technology. Annex 79 involves international researchers from diverse disciplines like engineering, architecture, computer science, psychology, and sociology. Annex 79 and this review paper have four main areas of focus: (1) multidomain environmental exposure, building interfaces, and human behavior; (2) data-driven occupant modeling strategies and digital tools; (3) occupant-centric building design; and (4) occupant-centric building operation. The objective of this paper is to succinctly establish the status quo of the above topics and articulate the most pressing research needs - planned to be addressed by Annex 79 and beyond.

\section{Introduction}

While most buildings are designed for human occupants, with the functions of providing comfortable, healthy, usable, and secure spaces to fulfill a variety of uses, human-building interaction remains one of the least mature facets of building science [1-3]. Numerous post-occupancy evaluations indicate that our buildings often do not meet expectations of occupants [e.g., 4]. For example, Huizenga, Abbaszadeh, Zagreus and Arens [5] reported that only 11\% of 215 buildings achieved $80 \%$ occupant satisfaction for thermal comfort and 26\% achieved that for indoor air quality. Since then, several studies [6-8] have yielded mixed, but generally positive benefits from green buildings. More research is needed not only on the fundamentals of occupant health and indoor environmental quality (IEQ) in buildings, but also on the processes and technologies required to transfer this knowledge to the way buildings are designed, constructed, and operated [9, 10]. This could be achieved through guidelines, recommendations for codes and standards, data-driven methods, (e.g., adaptive building controls), and new occupant models and simulation tools. Accordingly, these are the areas targeted by IEA-EBC Annex 79: Occupant-centric building design and operation.

While there has been a surge in research related to building occupants in the past decade, buildings remain to be designed and operated based on outdated and/or simplistic assumptions about occupants that are increasingly proving to be misguiding [11], such as the following. (Note that the cited papers for each point debunk or discuss the listed common assumptions.)
\end{abstract}


- Occupants are passive recipients of the indoor environment and optimal indoor environmental conditions can be described alone by physical parameters (e.g., air temperature, airspeed, relative humidity, contaminant concentration, workplane illuminance, sound pressure level) [12].

- Providing so-called ideal indoor environmental conditions can replace the need to provide occupants with control over their environment $[13,14]$.

- Controlling buildings based on average occupants is adequate for comfort [15].

- The four principal forms of IEQ (thermal, visual, and aural comfort and indoor air quality) can be treated individually, weighted equally, and they affect energy-related occupant behavior in a linear way [16].

- Given the opportunity to control building systems, occupants will use such systems in energysuboptimal ways; therefore, taking control away from occupants is an effective means to reduce energy use $[17,18]$.

- Buildings have uniform occupant distributions and near full occupancy for all or part of the day $[19,20]$.

- Occupancy and occupant behavior are uncertain during design and the most appropriate method to address this uncertainty in simulation-based design processes is to use standardized schedules and conservative assumptions [2, 21, 22].

In brief, a paradigm shift is required, whereby practitioners transition from seeing occupants as sources of indoor heat gains and contaminants who are content with standardized indoor environmental conditions to understanding that there is a complex and dynamic bi-directional interaction between occupants and buildings. This shift, which is presented in Figure 1, is supported by new knowledge, increased recognition of the value of healthy and comfortable environments, new enabling technologies and techniques (sensing and communication technology, analytical methods, computational power), and acknowledgement that occupants are an increasingly important factor for low-energy buildings.

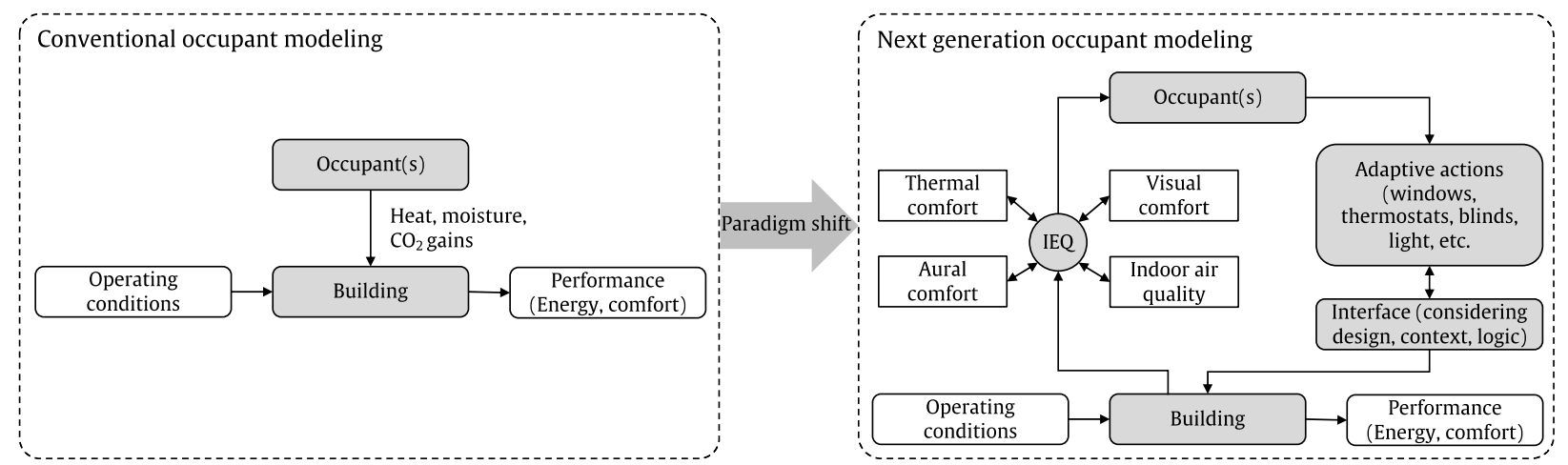

Figure 1: Paradigm shift from occupants and passive participants in buildings to active and dynamic elements in a complex twoway relationship

A surge of research on occupancy (i.e., human presence in buildings) and occupant behavior in the past decade has significantly advanced the state of knowledge in this field. For instance, IEA EBC Annex 79's predecessor, Annex 66, yielded the following advances:

- A quantitative representation and classification scheme (ontology) for measured building data, including occupants [23];

- A systematic approach to experimentally study occupancy and occupant behavior (including sensing technologies, data validation and management) [24]; 
- A systematic method for modeling occupants (including consideration of diversity between occupants) and evaluating models $[25,26]$;

- Various practical schema and implementations for incorporating occupant models in building performance simulation (BPS) tools [27, 28];

- A fit-for-purpose simulation framework for occupant-centric design [e.g., 29];

- A framework and survey for interdisciplinary approaches for studying occupant behavior [30, 31].

The full final report of Annex 66 [3], along with several review papers [32, 33] and special journal issues during the Annex 66 term provide an overview of the above activities. The outcomes are further summarized in Figure 2.

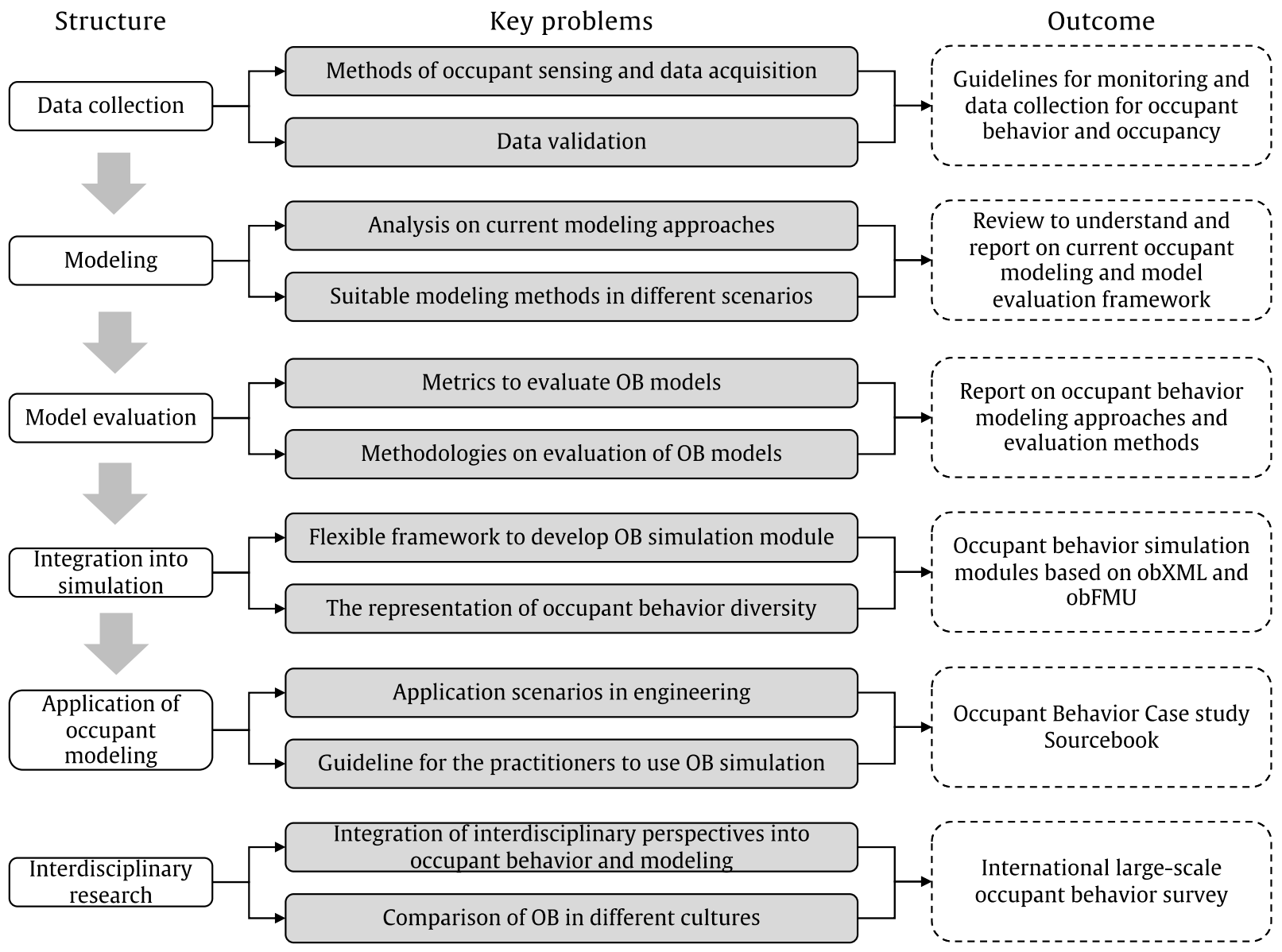

Figure 2: Summary of Annex 66 activities, problems addressed, and outcomes

Yet, more research is needed - particularly around the themes of multi-aspect comfort, human-building interaction through building interfaces; advanced sensing, big data, and advanced modeling; and occupant-centric building design and operations. Key questions discussed by this paper and that are being pursued by Annex 79 include:

- How do the different indoor environmental parameters (thermal, visual, olfactory, and aural comfort) affect each other in the context of energy-related occupant behaviors? For example, an occupant may be conflicted about opening a window for fresh air and the associated heat entering 
the space on a hot summer day.

- How do building interfaces, their context (e.g., positioning, ergonomics, number of people affected by controlled system), and their underlying controls logic affect behavior and perceived control? What interface features and characteristics are most effective at delivering a comfortable environment, outstanding perceived control, and reductions in energy consumption? What methods can be developed and used from established fields (e.g., human-computer interaction) to evaluate interfaces in laboratories, in situ, and through questionnaires? How should these results be disseminated to industry (e.g. via guidelines or building codes)?

- How can new and existing data sources (e.g., building automation systems, human resource databases, information technology networks, Internet of Things, etc.) and advanced data analytics (e.g., machine learning, artificial intelligence, statistical modeling) be exploited to both 1) develop new fundamental knowledge about occupant behavior, indoor environmental quality, energy, and the relationship between them, and 2) better inform building design and operation?

- How can simulation-aided building design processes, best practices, as well as energy codes and standards be advanced to encourage or mandate practitioners to properly account for occupants in order to yield more comfortable, healthy, usable, and energy-efficient buildings?

- How can building operations and controls be advanced to exploit new data sources and online learning methods to adapt to occupancy and occupant patterns and preferences to provide more comfortable environments using less energy?

The objective of this paper is to provide an overview of the state-of-the-art and most pressing needs in the field of occupant-centric building design and operation to the broader community. The structure of this paper approximately follows that of Annex 79 and is shown in Figure 3. The first two sections are of fundamental nature, considering IEQ, interfaces, behavior, data collection, and modeling tools and approaches. These are prerequisite to the second two sections, which focus on simulation-aided occupantcentric building design and on occupant-centric controls. These topics are quite broad and thus this paper focuses on the most critical issues, while relying on the other papers in this special issue to go into greater depth. The scope of the review and most urgent issues also extend beyond the plans of Annex 79.

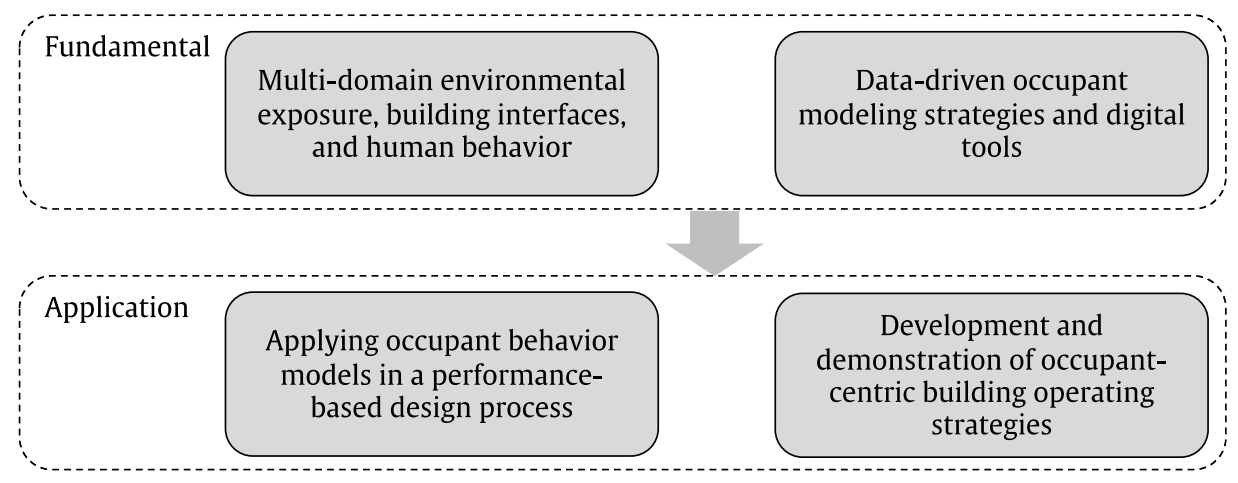

Figure 3: Structure of this paper and IEA EBC Annex 79 


\section{Multi-domain environmental exposure, building interfaces, and human behavior}

This section is focused on three main interrelated topics: fundamental research and research methods to study multi-domain indoor environmental exposure, guidelines for ideal indoor environmental quality, and the study and recommendation for building interface design to optimize energy performance, comfort, and usability.

\subsection{State of the art}

Occupants of buildings are exposed to a variety of distinct environmental exposures, among others thermal, visual, aural, and olfactory stimuli. An extensive body of literature (including review papers) deals with single-domain influences, such as thermal [34-37], visual [38, 39], or aural [40, 41] perception. In comparison, fewer research efforts have been conducted to explore multi-domain exposure situations. In a recent review of corresponding laboratory studies, Torresin, Pernigotto, Cappelletti and Gasparella [42] identified 45 studies published after 1990 dealing with two or more domains of exposures, with more than half dealing either with temperature and light (29\%) or temperature and noise (24\%). In the same period (1991-2019), over 1,000 research articles can be found via Science Direct, which have "thermal comfort" in the title. Consequently, the majority of standards and guidelines for indoor environment design support focus on single-domain influences, resulting in isolated treatment of indoor environments' multiple quality criteria.

In situations where the state of perceived environmental stimuli, for instance thermal sensation, does not match occupants' preferences and physiological or psychological adaptation is not sufficient to solve such discrepancy, they may opt for adaptive measures such as adjusting their position, body posture, or clothing level, or they may opt to interact with the building's envelope and systems through available interfaces [43-46]. Specifically, in order to support and improve buildings' energy efficiency through occupant behavior, buildings need to provide appropriate and user-friendly control opportunities via adequately designed and configured building envelope components and technical systems as well as corresponding effective human-building interfaces [47-49].

\subsection{Existing challenges}

The current state of knowledge and practice reveals a number of knowledge gaps and related research questions regarding building occupants' perceptual and behavioral phenomena [49-51]. Broadly speaking, these knowledge gaps may be formulated as follows:

i) As already noted in the previous section, the bulk of past research concerning human comfort and behavior in buildings treats the various domains of environmental exposure in isolation. Specifically, suspected environmental influence factors are subsumed and assessed under separate domains (e.g., thermal, visual, aural). In real situations, however, occupants are typically exposed to a combination of such factors. For example, window opening patterns have been related to indoor and outdoor thermal conditions. At the same time, the outdoor noise level can be expected to at least moderate the relationship between thermal conditions and window opening patterns [52]. Much about the implications of such multi-domain exposure situations on occupants' satisfaction, behavior and the energy use in buildings is still not yet understood.

ii) Regarding environmentally relevant design and engineering standards and guidelines for indoor spaces, it is often difficult to trace the entailed recommendations back to fundamental insights and studies in human biology, physiology, psychology, and sociology. This implies 
the need for more systematic explanatory theories of people's perception and behavior in the built environments that are rooted in sound underlying scientific knowledge [53].

iii) Buildings are expected to offer a wide range of indoor environmental conditions depending on external boundary conditions and user requirements. Toward this end, buildings are typically equipped with a number of environmental control devices, including both envelope components (such as windows and blinds) and mechanical and electrical systems [46, 54]. However, it can be argued that we have not paid enough attention to a critical feature of these systems, namely their user interfaces, specifically, their availability (to individual building occupants), visibility, intuitiveness, responsiveness, and effectiveness.

To summarize the above challenges, a deeper understanding of occupants' perceptual processes and behavioral patterns under multi-domain exposure situations is needed. Moreover, there is a need for a systematic approach to buildings' control interfaces in terms of their usability and potential to facilitate energy-conscious occupant behavior $[48,54]$.

These topical challenges are accompanied by methodological challenges. As compared to single domain research, multi-domain approach requires (a) deep knowledge in all relevant domains, (b) sensory equipment for field and laboratory studies, appropriate for capturing relevant influences in each domain, and (c) substantially more complex experimental designs that can capture the interrelations between one domain's influencing variables and those in other domains.

\subsection{Research priorities}

In the context of the existing knowledge gaps and challenges, Figure 4 outlines the two main topics to be investigated in detail: (1) multi-domain environmental exposure and its effect on human perception and occupant behavior, and (2) the interactions between occupants and building interfaces related to the buildings' environmental control systems.

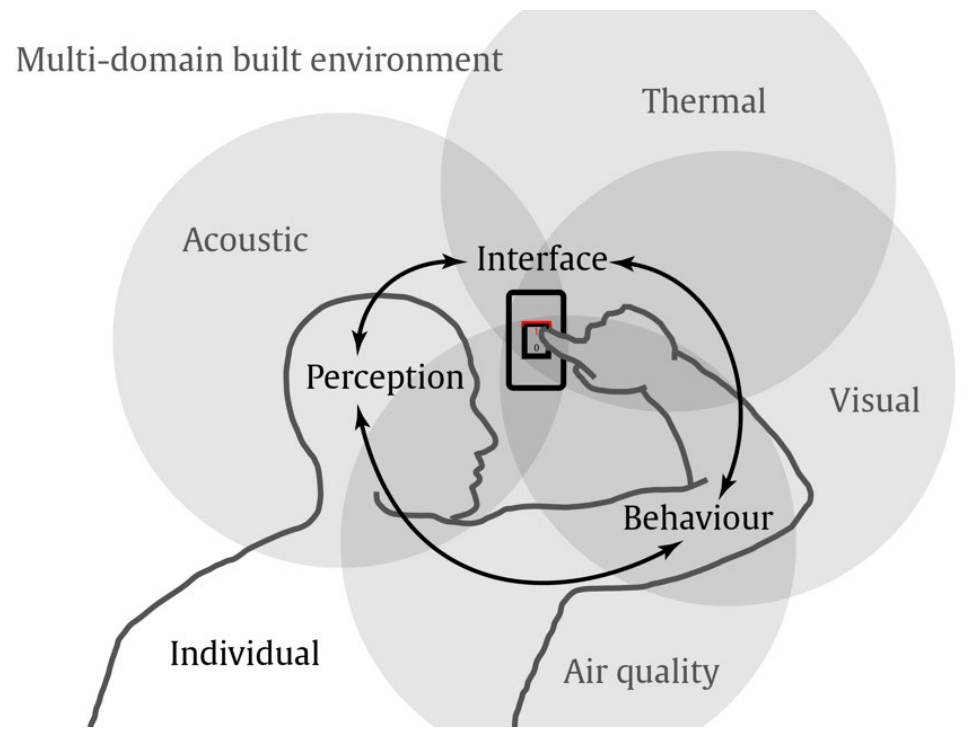

Figure 4: Schematic illustration of research foci (multi-domain exposure, human perception and behavior, building systems' interfaces).

The state-of-the-art review has identified a number of knowledge gaps concerning the multi-domain nature of indoor environmental exposure, the relevance of respective perception and behavior models, and the typology and utility of interfaces for buildings' control devices. Moreover, a number of necessary 
foundational state-of-the-art reviews have been conducted to address these gaps [49-51]. Consequently, research specific priorities are emerging, which are briefly described as follows.

(1) to develop a unified theoretical framework for perceptual and behavioral theory of building occupants;

(2) to establish general empirical research methods guidelines for developing a better understanding of occupants' comfort preferences and behavioral patterns under multi-domain exposure situations in buildings;

(3) to provide a systematic categorization scheme for common control-oriented building interfaces and to collect and present best-practices for building interfaces, together with interface design and evaluation criteria of new products considering multi-domain comfort;

(4) to document occupancy-related information relevant to the building design, construction, and operation processes;

(5) to explore the potential of a versatile agent-based modeling platform.

These priorities are described in the following in more detail.

\subsubsection{A unified theoretical framework for perceptual and behavioral theory of building occupants}

Occupants' perception and behavior is investigated by different disciplines, ranging from engineering to social sciences. Underlying theories are more often explicitly mentioned in social sciences compared to engineering work, where theoretical thoughts may drive decisions such as selecting observed variables, but are not explicitly mentioned in the majority of literature. The majority of literature from engineering is concerned with physical variables [45]. Research in social sciences suggests that different psychological factors may drive human behavior and interactions with the surrounding environment. Bringing such perspectives together into buildings, occupant behavior and interactions with building systems can be motivated by different psychological factors, resulting in different operation modalities of control devices (luminaires, radiators, blinds, etc.) and respective energy use. Therefore, the first priority is to review scientific theories (from physiology to psychology and sociology) to explain what factors may explain occupants' behavior in view of interactions with buildings' environmental control systems and to develop a unified framework. Thereby, aside from the physical setting and physiological state of the human subjects, special attention must be paid to psychologically and socially relevant parameters that may encourage or discourage occupants from engaging in control-oriented adaptive actions.

Developing this unified research framework will guide future activities, enhance communication between different disciplines, and at the same time, will remain open for additions and adjustments based on new findings through collaborative works or from individual disciplines.

\subsubsection{Guidelines and additional research related to empirical research methods for multi- domain exposure situations in buildings}

The initial assessment of the state-of-art of existing models (and associated practice-oriented standards and guidelines) regarding human perception, comfort, and behavior suggests the pervasiveness of singledomain thinking. This, however, does not mean that there have not been previous efforts to explore multidomain exposure situations and their implications for human comfort [42, 55-57].

Any future progress in this area could benefit from general guidelines for empirical research methods, which is the second priority of the research agenda. Specifically, guidelines for future studies that concurrently consider multiple environmental stressors, their impact on human sensation and perception processes, their relevance for the formation of adaptive dispositions, and the potential for realization of 
such dispositions via interactions with control device interfaces. Such guidelines could set minimum requirements for related research activities, support future researchers to avoid previous mistakes, and enhance the comparability across studies, as these studies would be based on common methodological thoughts. Furthermore, such guidelines could offer insights from research design to minimum requirements for reporting research results, such as the inclusion of discussion of non-significant results and reporting effect sizes as important additions to levels of significance.

\subsubsection{Categorization and assessment of control-oriented building interfaces}

A better understanding of interfaces and how occupants use them can inform efforts to encourage desirable user behavior patterns that can bring about preferable indoor environmental conditions from occupants' perspective while meeting the operational efficiency criteria. Therefore, the third priority is to characterize how occupants interact with different types of building interfaces (i.e. structural interfaces, control interfaces/building services, and active digital interfaces) and how, thereby, opportunities for energy savings, increased occupant control, both perceived and real, and comfort can be recognized and exploited. This priority also extends to cover the review and processing of experiences in the area of behavior change, feedback (e.g. feedback via screens, red/green light, etc.), and control (e.g. perceived/actual; automated vs. manual). A related challenge, in the area of building interfaces and associated occupant behaviors, is the problem of effectively measuring a building's quality and usability as related to its embedded user control interfaces. There is arguably a lack of generally agreed-upon evaluation procedures for this aspect of buildings' indoor environment, namely its controllability by building users, or - in the terminology of Human Ecology - its "Ecological Valency" (EV) [58]. The potential for designing and implementing formal procedures toward measurement and certification of indoor environments' EV [46, 54, 59] will be actively pursued by Annex 79 researchers.

\subsubsection{Documentation of existing information concerning occupants' requirements}

The literature shows that occupants can significantly influence buildings' energy use [60]. Nonetheless, the building delivery process (including the design, construction, and operation phases) does not appear to be sufficiently informed concerning the building users' needs, requirements, expectations, perceptual characteristics, and behavioral patterns. In the initial discussions preceding the formation of Annex 79, the lack of sufficiently rich procedures and informational repositories concerning such occupancy-related requirements and characteristics was found to be potentially detrimental to evidence-based building design and operation processes. Therefore, another priority is to collect salient information concerning the existing procedures and sources available to building design, engineering, and management professionals concerning occupants' needs and requirements at an international level.

\subsubsection{Agent-based modeling platform}

Occupancy-related factors can significantly influence buildings' performance. Hence, the representation of building users is a critical aspect in simulation applications that deal with buildings' energy and indoor environmental performance. In recent years, researchers have argued for more sophisticated user-related building simulation input data. Thereby, stochastic behavioral models have been considered as alternatives to conventional schedules and simple rule-based assumptions. Compared to the conventional static schedules, stochastic occupancy models can provide a more realistic depiction of the dynamically changing patterns of occupants' presence and actions in buildings [45, 61]. Moreover, agent-based formalisms have been promoted to provide a flexible and powerful way to capture the complexity of individual users' presence and behavior in buildings. Aside from the potential to enrich advanced building simulation model development efforts, a platform for a systematic and coherent representation of occupants' presence and actions in building via deployment of agent-based modeling techniques can provide a powerful virtual testbed for examination and evaluation of multi-domain occupant comfort and 
behavior models. Thereby, the aforementioned theoretical and empirical findings, regarding the perceptual and behavioral repertoire of buildings' inhabitant, may provide an underlying basis for the encapsulation of occupants' attributes and behavior in terms of computationally defined dynamically acting agents [62].

\section{Data-driven occupant modeling strategies and digital tools}

The advancement and pervasive deployment of new sensing modalities, computing platforms, information technologies and the digitization of the society enable many new sensing technologies and data sources about occupant presence and actions [63, 64]. This advance enables a research paradigm shift towards data-driven modeling of occupant presence and behaviors. This section describes research priorities with regards to knowledge, strategies and tools to seize these opportunities.

\subsection{State-of-the-art}

\subsubsection{Occupant Sensing}

Work in IEA EBC Annex 66 reviewed the properties of sensor modalities and general protocols for collecting occupant-centric data using sensors [24]. The general focus was on enabling domain experts to choose sensors to optimize the accuracy or other properties of the collected data. In any deployment, trade-offs have to be made among accuracy, privacy invasiveness and the cost of data collection (e.g., building installed versus tenant/occupant owned sensors) [64]. A recent review on current building occupant sensing systems indicates that commercially available occupant sensors are still too expensive to deploy at the whole building level (Dong et al. 2019). The large potential for energy savings from occupancy-based HVAC and lighting controls [65], ranging from $20 \%$ to $50 \%$, however motivates researchers to investigate new sensors or new approaches for occupancy sensing. Most research studies focus on a small-scale deployment using prototype sensors. A notable recent study is to utilize WiFi probe technology to actively scan the WiFi connection request and response between WiFi signals and smart devices in existing network infrastructures. The results show that more than $90 \%$ of the time, up to four occupants in a space can be detected [66]. Another direction is to integrate sensor modalities to address the limited coverage of high-accuracy sensors with wide-coverage inaccurate sensors [67].

\subsubsection{Data-driven Modeling for Occupant Presence and Behavior}

The wealth of data opens new opportunities for extracting knowledge through data-driven modeling of occupant presence and actions. In particular, the many opportunities offered by data mining and artificial intelligence creates a humus for the development of new models or for generating new knowledge on multi-aspect environmental exposure, human-building interfaces, human behavior, and occupant-centric building design and operation. Data mining and artificial intelligence are fostering a rapid development and penetration of new methods and tools that can identify patterns and learn from the past, have better properties and performances, or make analytical and predictive techniques easily accessible on more powerful computing infrastructure [68].

While IEA EBC Annex 66 focused on traditional methods for modeling occupant presence and actions, future research should also embrace machine learning techniques including supervised and semisupervised learning for classification and regression and unsupervised clustering for pattern analysis of occupant behavior. Previous work has documented the challenges in selecting the best data processing methods and in knowing when data-driven methods are the appropriate tool, for example, for predicting occupant presence [69] or for model-predictive control [70, 71]. Furthermore, while a most studies use metrics for quantifying the properties and accuracy of a model [72], the field lacks a structured and 
coordinated overview with the identification of the main limitations of the data-driven methods commonly used in occupant presence and action modeling.

\subsubsection{Open Data-driven Science}

Data is the foundation of data-driven models. Therefore, science and domain experts must establish means of sharing data and software to alleviate researchers and organizations from the burden of collecting redundant data for research purposes. Sharing data and software will increase transparency and reproducibility of science [73]. To share and use data in a consistent manner requires that organizations agree on documentation of the meaning of data, e.g., a metadata schema. Existing work has considered schemas for building instrumentation in general [74] and building monitoring with an emphasis on building occupants, outdoor and indoor environmental conditions [23]. A threat when sharing data is the possible violation of individuals' right to privacy. Existing principles and regulations must be observed, such as, the Findable, Accessible, Interoperable and Reusable (FAIR) principles and the EU General Data Protection Regulation (GDPR). Existing work has considered methods to anonymize released data to minimize possible violations. PAD is one example of an anonymity system based on the principle of kanonymity [75]. However, there remain major gaps in that open science methods are not well established in the field, no proper metadata schema exists, privacy protection methods do not protect against a range of threats, and the methods are not easy applicable by domain experts.

\subsection{Existing challenges}

The review points to a list of research needs and associated activities as illustrated in Figure 5.

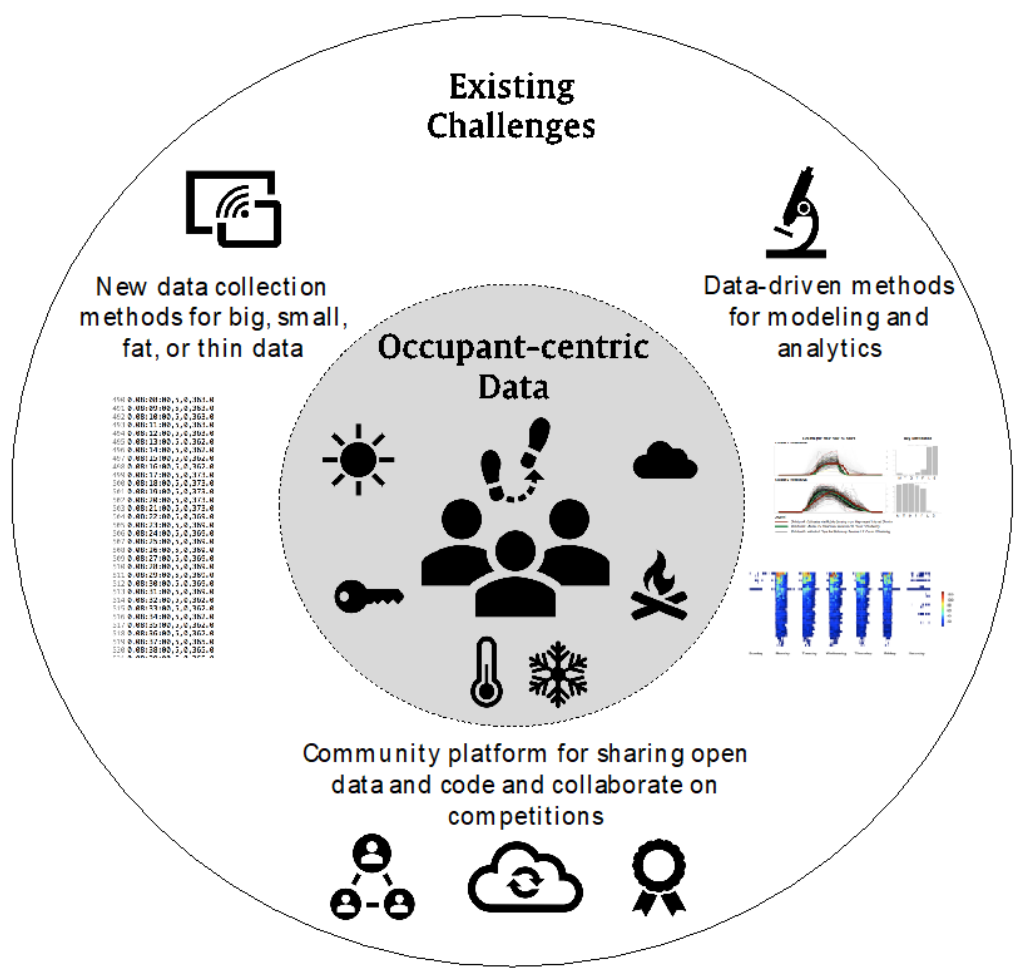

Figure 5: Overview of challenges and actions

A challenge with data-driven modeling is that there are lacking scalable data collection solutions for a large-scale occupant behavior modeling; especially when considering the many types of data from small 
to big from thin to fat. With the development of the Internet of Things, researchers start looking at potential data from mobile phones and social media-based data. Recently, research on urban mobility uncovered the potential to derive occupancy locations using mobile position data [76]. To address this, the Annex 79 will develop new occupancy data collection methods including scalable data sources, such as, mobile position and social media data.

Another challenge is that, by borrowing methods from other fields, there is a wealth of data-driven methods for modeling and analysis. However, a coherent and thorough picture of the methods used for occupant presence and action modeling is lacking. This gap can -among other things- result in using inferior or outdated methods, or in incomparable results if different methodologies are applied. To address this challenge, a synoptic table from review studies will be created which relates methods, purposes and accuracy metrics, together with the identification of the limitations of data-driven methods commonly used in occupant presence and action modeling.

Furthermore, to foster a proper use of data-driven methods, the elements of a data processing tool chain will be distilled for data-driven models representing occupant presence and action. The scope has to cover different methods, including classification, regression, clustering and preprocessing of data; for example, cleaning of data from faulty, misplaced sensors or sensors that have been tampered with. To promote the adoption of these novel approaches for exploiting data processing for occupant presence and action modeling, application guidelines have to be provided to support occupant-centric building design, simulation and control, from the collection of in situ occupant-centric sensing data to the visualization of data and outcomes.

A final challenge is to apply an open science methodology to data-driven modeling of occupant presence and behavior, as lack of openness can lead to research results that are not transparent in terms of data and resulting models. This challenge can be broken into several issues, including lacking availability of open data and experience using open data; lack of structured metadata to support releasing and using open data; and handling of privacy issues when releasing data. Efforts to address this challenge will include the development of a community platform to share open data and code for modeling occupant behavior and actions. This will be supported by creating metadata schemas for annotating data and querying data for various use cases. Furthermore, the state-of-the-art of anonymization methods for preprocessing released data will be advanced to improve occupant/participant privacy. Finally, to build a research community, data competitions will be organized to involve researchers and people from practice and to create awareness about the released data and code.

\subsection{Research priorities}

\subsubsection{Utilization of scalable data sources}

To address scalable data collection solutions, a few research studies have been investigated that utilize data from mobile phones such as position and social media data and WiFi signals $[77,78]$. The purpose is to provide a guideline for future researchers on a scalable and large-scale data collection solution. As a starting point, several universities within IEA EBC Annex 79 have been collaborating on collecting those data from different countries. As a case study, mobile position data were collected through installed mobile phone apps in two cities, San Antonio, USA and Beijing, China. From that, daily occupancy schedules for 453 buildings in the San Antonio downtown area have been derived. In order to quantify the difference between these schedules and pre-defined schedules from design standards and guidelines (e.g., ASHRAE Standard 90.1 [79]) a new statistical measure, called discrepancy score and absolute mean discrepancy score has been developed. The preliminary results from the 453 buildings show that the maximum hourly difference between those two schedules is up to $36 \%$ while the average difference is 
about $8 \%$ [76]. Moving forward, the energy impacts of inaccurate schedules will be evaluated at a large scale. In addition, the installation of actual occupancy sensors is planned to evaluate the accuracy derived from mobile position data.

\subsubsection{Data-driven methods for modeling occupants}

To address data-driven methods for modeling and analysis a systematic literature study has been designed and conducted. The purpose is to collect those studies that investigate the widefield of occupant presence and action modeling. The CIMO-logic (context, intervention, mechanism, outcome) was used according to the guideline proposed by Denyer, Tranfield and van Aken [80] to frame the research question: "How do we model (M) the occupant presence and behavior (I) to simulate the (energy, comfort etc.) performance (O) of buildings (C)?" Overall, more than 700 journal and conference papers and reviews were collected and analyzed using data-driven methods and digital tools like Bibliometrix [81] and VOSviewer [82]. This collection of scientific products has provided information on how stochastic and data-driven methods have been used so far for occupancy prediction (detection and estimation), window and solar shading operation, daylight and artificial lighting use, electric appliance utilization, thermostat adjustment, and clothing insulation estimation. A next step is to investigate the metrics used for model accuracy estimation and for detecting the main limitations affecting the adoption of several classes of methods to occupant presence and behavior modeling.

\subsubsection{Open Science Methodology}

This topic focuses on supporting an open science methodology to data-driven occupant modeling. A survey has been launched to gather research community feedback on existing practices, barriers and opportunities. Existing practices cover software tools and using and sharing of open datasets. Barriers cover different challenges in either sharing or using open data. Opportunities cover new possibilities for using or sharing data. The survey results will help to address the highest ranked barriers and opportunities. Another initiative is as a community to start sharing data and software resources within the area: github.com/EBC-Annex-79/Data-Driven-Occupant-Modeling. Some of the released data has already been analyzed in terms of privacy protection. The analysis demonstrates the many challenges in anonymizing data as several variables of a released dataset could be re-identified [83]. Therefore, solutions to better anonymization of data is an ongoing focus in future work.

\section{Occupant-centric building design}

From the IEA-EBC Annex 79 perspective, occupant-centric building design means to place occupant needs (comfort and health) as a priority and to use explicit occupant behavior modeling to design for and recognize the bi-directional interaction between occupants and buildings.

\subsection{State-of-the-art}

As mentioned in the outset, in the past decades understanding and modeling of occupant behavior has gained momentum [33]. A new generation of data-driven models aim to capture the interactive relation between occupant and built environment which is, in particular, advantageous for occupant-centric design. Additionally, further possibilities for implementation of occupant behavior models in building simulation tools are emerging $[44,84]$. Besides, given the concerns about the reliability of occupant behavior models in different contexts $[85,86]$, an increasing number of cross-validation studies have put the existing occupant behavior models to the test [87]. IEA-EBC Annex 66 [3] represented a major coordinated effort to improve the status quo in this regard. However, occupant modeling in simulation for design purposes remains in its infancy. 
Applying a new generation of occupant behavior models in the building design process provides many opportunities to not only improve energy prediction but also to better understand how occupants will respond to various architectural and controls concepts. It follows that building design can be greatly improved with regards to energy performance and occupant comfort. In addition, the advent of advanced occupant modeling opens many new opportunities to pursue novel design procedures, such as robust design, design optimization, and generative design [88-90].

More specifically, the building design process includes several important activities that involve obtaining information and making assumptions about occupant schedules and their activities in buildings. For example, occupant-related assumptions are used for load calculations to estimate peak cooling, heating, and ventilation loads in designing HVAC systems. Similarly, to meet the targets specified in performance-based building energy codes, building designers rely on building energy and occupant models to simulate and compare performance of the proposed design with the code baseline. Currently, basic non-customized schedules are used in most design calculations and associated decision-making processes. With the advance in dynamic and stochastic modeling of occupants' presence, movement, comfort needs, and occupants' interaction with building systems and devices, these models can be used to support the design of buildings that are energy efficient, comfortable and usable, flexible to shift loads, and resilient to extreme weather events (e.g., heatwaves, wildfires).

\subsection{Existing challenges}

In spite of the aforementioned advances in capturing the occupant behavior complexity, the latest studies in the field suggest that application of occupant models in the design process is still in its infancy [32]. Specifically, while the deeper insight to occupant behavior has resulted into popularity of stochastic models in the research community, use and analysis of stochastic results remain one challenge in the field. Besides, with the expanding pool of occupant models, building performance modelers face the additional question of choosing the right occupant behavior model for building simulation in the design process [29]. In fact, from the authors' view, the increasing number of published occupant behavior models has not provided widely applicable approaches to represent occupants across different building types, climates, cultures and settings, as they lack a cohesive meta-data companion for application in building design and operation practice [85].

\subsection{Research needs}

There is an urgent need to develop, demonstrate, and deploy methodologies, technologies, and policies to design occupant-centric buildings that are comfortable, usable, adaptable, and energy efficient. Research should specifically address the sustainable implementation of occupant behavior models in building practice by developing guidelines (and preparing standards) for applying the models during building design and operation. In addition, focused case studies should be used to implement and test the new models in different design and operation phases in order to get valuable feedback for the researchers and ultimately to normalize the practice of occupant-centric design.

In detail, as shown in Figure 6, key planned research activities with regard to occupant-centric building design are structured as literature reviews, supporting explorations, development of methods or recommendations and case studies. 


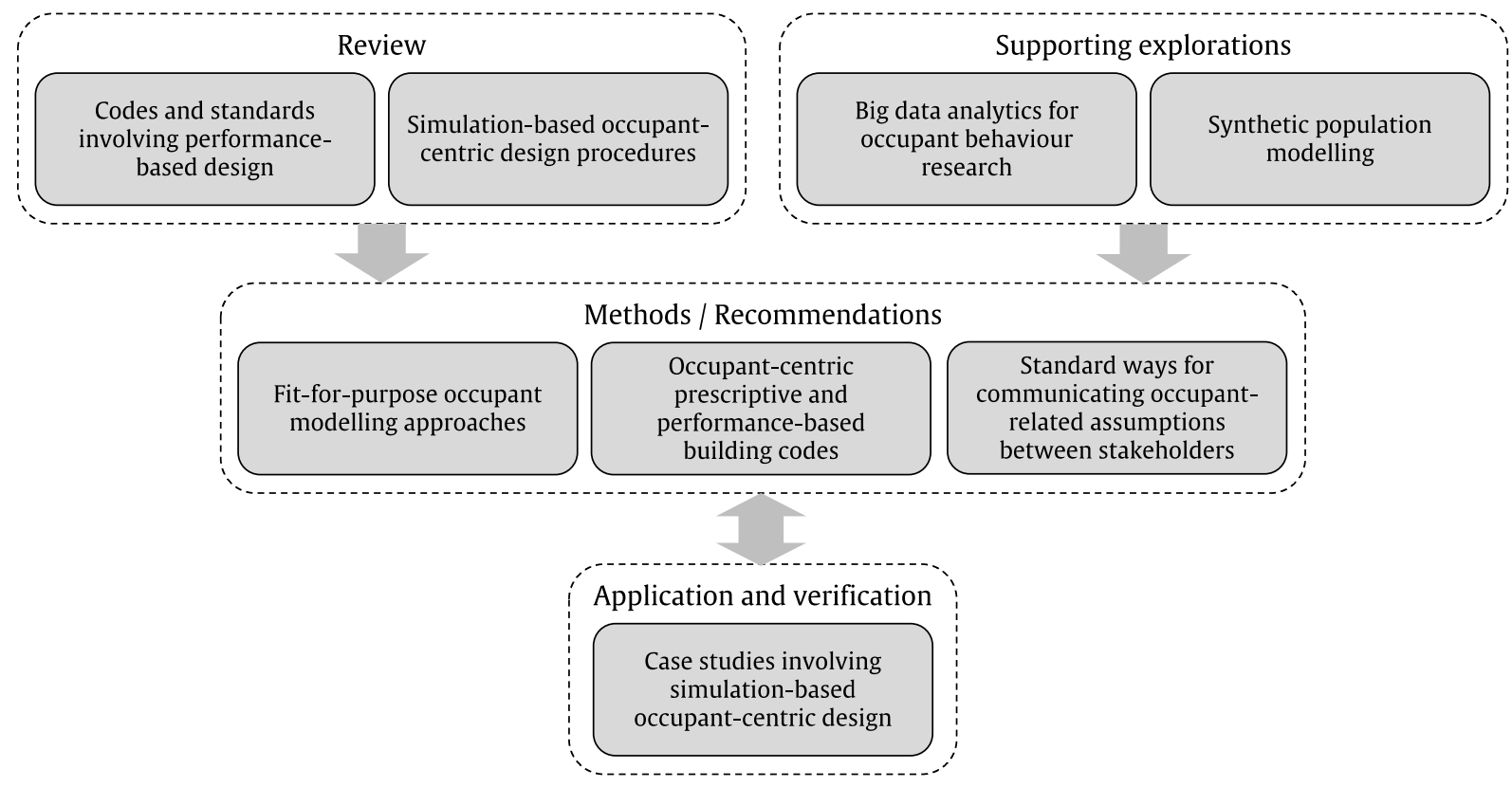

Figure 6. Flowchart of IEA-EBC Annex 79 activities with regard to occupant modeling in building design

\subsubsection{Literature reviews}

Two literature reviews on occupant-centric design have been performed to provide the basis for development of methodologies and recommendations for consideration of occupants and application of occupant behavior models in building design process. Firstly, a comprehensive international review of occupant representation in building codes and standards investigates and analyses global experiences of treating occupants in the regulations associated with performance-based design process. Occupant-related details in 22 countries' building energy codes have been collected and analyzed. Table 1 summarizes the numeric occupant-related information found in the building energy codes from this review [91].

The second review [88] collected and investigated previous efforts in a variety of computational design support methods (including robust design, parametric design and optimization) with a focus on the role of occupants. The review explored occupant-related building performance metrics, modeling and simulation approaches, design methods and applications together with the supporting mechanisms associated with occupant-centric design and identifies the barriers for more effective application of occupant-centric building design practices.

Table 1. Occupant-related assumptions in building energy codes in 22 countries

\begin{tabular}{|c|c|c|c|c|c|c|c|c|c|}
\hline Country & $\begin{array}{c}\text { People density or } \\
\text { heat gain } \\
\text { [person } / \mathbf{m}^{2} \text { ] }\end{array}$ & $\begin{array}{c}\text { Lighting power } \\
\text { density } \\
{\left[\mathbf{W} / \mathbf{m}^{2}\right]}\end{array}$ & $\begin{array}{c}\text { Equipment } \\
\text { power } \\
\text { density } \\
{\left[\mathbf{W} / \mathbf{m}^{2}\right]} \\
\end{array}$ & $\begin{array}{c}\text { Hot water } \\
\text { consumption } \\
{\left[\mathrm{l} /\left(\mathbf{d} \cdot \mathbf{m}^{2}\right)\right]}\end{array}$ & $\begin{array}{c}\text { Recommended } \\
\text { ventilation rate } \\
{[\mathrm{I} /(\text { s.person })]}\end{array}$ & $\begin{array}{c}\text { Cooling } \\
\text { setpoint } \\
{[\mathrm{C}]}\end{array}$ & $\begin{array}{l}\text { Heating } \\
\text { setpoint } \\
{[C]}\end{array}$ & $\begin{array}{c}\text { Cooling } \\
\text { setback } \\
{[\mathrm{C}]}\end{array}$ & $\begin{array}{c}\text { Heating } \\
\text { setback } \\
{[\text { [C] }}\end{array}$ \\
\hline AUS & 0.10 & $9.0,7.0^{1}$ & 15.0 & $4.0 \mathrm{l} /($ d.person) & 10 & 26.0 & 18.0 & off & off \\
\hline AUT & $1.7 \mathrm{~W} / \mathrm{m}^{2}$ & $25.76 \mathrm{kWh} /\left(\mathrm{m}^{2} . \mathrm{a}\right)$ & 1.3 & $9.0 \mathrm{Wh} /\left(\mathrm{m}^{2} . \mathrm{d}\right)$ & $1.051 / \mathrm{h}$ & 26.0 & 22.0 & off & off \\
\hline BEL & 0.07 & 6.0 & 3.0 & $5.0 \mathrm{MJ} /\left(\mathrm{m}^{2} . \mathrm{a}\right)$ & 6 & 25.0 & 21.0 & $28^{2}$ & $\begin{array}{l}15^{\text {Error! }} \\
\text { Bookmark }\end{array}$ \\
\hline BRA & 0.10 & 14.1 & 9.7 & - & 7.5 & 24.0 & - & off & - \\
\hline CAN & 0.04 & 8.5 & 7.5 & $90 \mathrm{~W} /$ person & 8.5 & 24.0 & 22.0 & off & 18.0 \\
\hline
\end{tabular}

${ }^{1}$ Respectively for spaces that require more and less than 200 lux.

2 The given value is for low inertia buildings. For high inertia buildings no heating or cooling setback temperature is assumed. 


\begin{tabular}{|c|c|c|c|c|c|c|c|c|c|}
\hline CHE & 0.07 & 15.9 & 7.0 & $3.01 /($ d.person) & 10 & 26.0 & 21.0 & off & off \\
\hline $\mathrm{CHN}$ & 0.10 & 9.0 & 15.0 & $5-101 /($ shift.person) & 8.33 & 26.0 & 20.0 & off & off \\
\hline DEU & 0.07 & $\mathrm{n} / \mathrm{a}^{3}$ & 7.1 & 0.70 & $1.8 \mathrm{l} /\left(\mathrm{s} \cdot \mathrm{m}^{2}\right)$ & 24.0 & 21.0 & off & 17.0 \\
\hline DNK & $0.044^{4}$ & 11.0 & 6.0 & 0.27 & 7 & 25.0 & 20.0 & off & - \\
\hline ENG & 0.11 & $n / a^{5}$ & 11.8 & 0.20 & 10 & 24.0 & 22.0 & off & 12.0 \\
\hline FRA & 0.10 & - & 16.0 & 0.18 & 7 & 26.0 & 19.0 & 30 & 16,7 \\
\hline HUN & $n / a^{7}$ & $11.0 \mathrm{kWh} /\left(\mathrm{m}^{2} . \mathrm{a}\right)^{8}$ & $\mathrm{n} / \mathrm{a}$ & $9.0 \mathrm{kWh} /\left(\mathrm{m}^{2} . \mathrm{a}\right)$ & 7 & 26.0 & 20.0 & - & - \\
\hline IND & 0.05 & 10.0 & - & - & 8.5 & 26.0 & 18.0 & - & 12 \\
\hline ITA & $0.05-1.0^{9}$ & - & 15.0 & 0.2 & 11 & 26.0 & 20.0 & - & - \\
\hline KOR & 0.05 & $15.8^{10}$ & $12.9^{10}$ & $0.237^{10}$ & 8.05 & 28.0 & 20.0 & - & - \\
\hline NLD & 0.06 & - & 4.0 & $65 \mathrm{l} /\left(\mathrm{m}^{2} . \mathrm{d}\right)$ & $1.31 /\left(\mathrm{s} . \mathrm{m}^{2}\right)$ & 24.0 & 20.0 & off & 18.0 \\
\hline NOR & $50 \mathrm{Wh} /\left(\mathrm{m}^{2} . \mathrm{d}\right)$ & 9.6 & 13.1 & $19.22 \mathrm{Wh} /\left(\mathrm{m}^{2} . \mathrm{d}\right)$ & $1.94 \mathrm{l} /\left({\left.\mathrm{s} . \mathrm{m}^{2}\right)}^{2}\right.$ & 24.0 & 21.0 & - & 19.0 \\
\hline NZL & 0.06 & 12.0 & 8.1 & - & 10 & $22 \pm 1.5$ & $21 \pm 1.5$ & - & - \\
\hline SGP & $0.1,0.06^{11}$ & 12.0 & 16.0 & - & $0.61 /\left(\mathrm{s} . \mathrm{m}^{2}\right)^{12}$ & $23,25^{13}$ & - & off & - \\
\hline SWE & 0.05 & $7.6,3.2^{14}$ & $11.6^{15}$ & $2 / \eta \mathrm{kWh} /\left(\mathrm{m}^{2} . \mathrm{a}\right)^{16}$ & $1.31 /\left(\mathrm{s} . \mathrm{m}^{2}\right)$ & 23.0 & 21.0 & off & off \\
\hline UAE-1 & 0.05 & 8.7 & 8.1 & - & 8.5 & 23.9 & - & 26.7 & - \\
\hline UAE-2 & 0.05 & 10.0 & - & - & 8.5 & 24.0 & - & - & - \\
\hline USA & 0.05 & 11.06 & 8.1 & $4.161 /($ d.person $)$ & 8.5 & 23.9 & 21.1 & 26.7 & 15.6 \\
\hline
\end{tabular}

\subsubsection{Supporting explorations}

The aforementioned reviews are accompanied by two supporting investigations in the field of big data analytics and synthetic population modeling to further explore possibilities for application of occupant behavior modeling in building design process.

Firstly, given the costs and uncertainties associated with measuring the total number of occupants in buildings through traditional methods [93,94], availability of social media data can provide alternative solutions. Social media data has been researched for urban mobility and disaster evacuation, for example, to provide new insights in areas including travel recommendation, industrial competitive analysis and activeness identification [95-97] (Majid et al. 2013; Yang et al. 2018, Pohl et al. 2018). One exploration in Annex 79 aims to study the possibilities of using social media data to derive occupancy patterns of buildings through integrating location analysis and data mining methods (see also Section 3.3.1). This will include data collection and cleaning of social media data, extraction and analysis of location of people, occupant numbering extraction and validation for a commercial building. In this context, there is a lack of systematic methods to analyze social media data to derive schedules at different time scales for both building design and operation purposes, which will be addressed by this activity.

Secondly, while synthetic population models are used in other disciplines, e.g., demography, transportation, and psychology, no such study can be found in the building energy field. Based on a literature review on synthetic population models in other fields, this activity focuses on designing and developing a synthetic population model of building occupants to support occupant behavior modeling and simulation in buildings. The activity reviews the existing datasets that can be used to populate the

${ }^{3}$ Lighting power is calculated based on office geometry and other parameters according to a simplified calculation routine referred to as efficiency procedure. ${ }^{4}$ Derived based on stated values of $4 \mathrm{~W} / \mathrm{m}^{2}$ for internal heat gain by occupants and $90 \mathrm{~W} /$ person for metabolic rate.

${ }^{5}$ Power density is calculated based on lighting with efficacy of 60 luminaire lumens per circuit-watt and a regression-based function for zone geometry.

616 for off periods less than 48 hours, 7 for off periods more than 48 hours.

${ }^{7}$ Internal heat gains from people, lighting and equipment are not specified, only a single value of $7 \mathrm{~W} / \mathrm{m}^{2}$ is given for all internal heat gains

${ }^{8}$ It can be multiplied by 0.7 in case daylight, occupancy or movement sensors are installed.

${ }^{9}$ The code offers five classes of occupant density $(1,0.4,0.18,0.07$ and 0.05$)$ for non-residential buildings.

${ }^{10}$ Based on a research effort on reference building energy models for South Korea [92] D. Kim, Y. Kim, S. Lee, W. Park, Y. Bok, S. Ha, S. Lee, Development of

Reference Building Energy Models for South Korea, Proc. of the 15th IBPSA Conf, 2017, pp. 2693-2700.

${ }^{11} 0.1$ for admin/general office room, 0.06 for director/manager room.

${ }^{12}$ Maximum of $0.6 \mathrm{l} /\left(\mathrm{s} . \mathrm{m}^{2}\right)$ and $5.5 \mathrm{l} /(\mathrm{s}$. person).

1323 for zones with solar gain, 25 for other zones

147.6 for efficient lighting, 3.2 for very efficient lighting.

15 The given value is based on estimated average power of medium level.

${ }^{16} \eta$ is the annual efficiency of hot water production. 
models, including the ASHRAE Global Thermal Comfort Database II [98] and Annex 66 Occupant Behavior Survey [99]. Gaps in the dataset will be identified and a plan to collect the needed data will be developed, which is in line with the proposed effort to develop a global occupant database.

\subsubsection{Methods and recommendations}

As shown in Figure 6, future research aims to develop three sets of guidelines and recommendations for occupant-centric design as follows:

1. Guidelines to choose fit-for-purpose occupant modeling approaches;

2. Recommendations for occupant-related prescriptive and performance paths of building codes;

3. Standard ways for communicating occupant-related assumptions between stakeholders.

Following IEA EBC Annex 66 efforts [29], Annex 79 aims to establish reliable paths to choose the most appropriate occupant modeling approach across scales, building types, design stages, climates, and building modeling objectives. Additionally, while Annex 79 does not seek to re-write building codes, it aims to provide concrete recommendations on how occupant-related considerations can be advanced in building codes to code committees around the world. This activity aims to extract effective and applicable recommendations for building energy codes based on the outcomes of the literature reviews explained in Section 4.3.1. These recommended procedures and guidelines will be applied and verified in a number of real-world case studies as explained in the following section.

\subsubsection{Case studies}

Occupant-centric design methods are greatly needed, and this notion is supported by the literature. However, it is important to demonstrate them in practice to: 1) show that they can work on real buildings (e.g., not merely shoebox office models), and 2) publicize the importance of occupant-centric simulationaided design to a variety of stakeholders, such as building developers, architects, engineers, and energy modelers. Accordingly, Annex 79 plans to apply and verify the developed methods to real building design projects with stakeholder involvement. After having established the criteria for selection of case studies, the researchers have selected approximately six buildings for further study. Figure 7 shows the location of the planned case studies in the context of the life cycle phase of the building that they are focused on and the study spatial scale. While the case studies are diverse in building type, location, and focus, they share the common attribute of applying modeling and simulation methods to improve building design, with a focus on occupants. The case studies and applied design methods will be documented in detail and disseminated widely to demonstrate the importance and value of occupant-centric building design. 


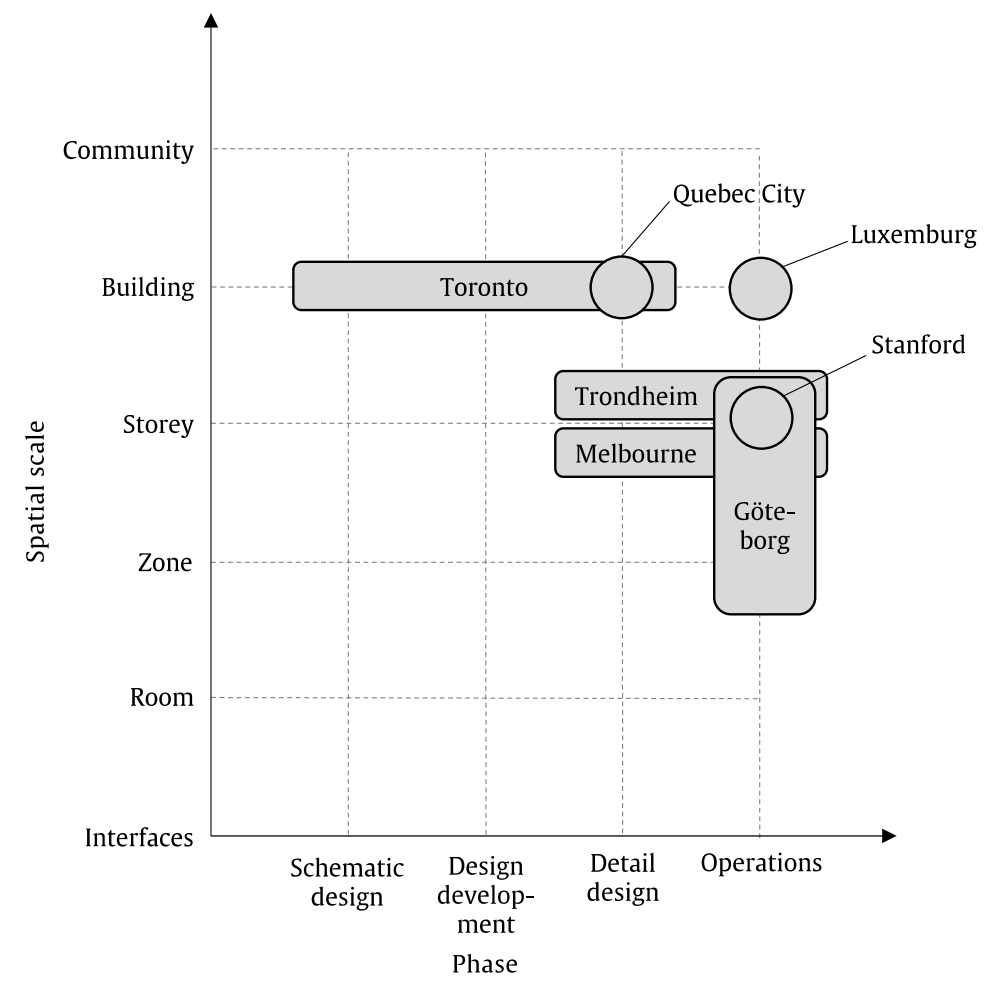

Figure 7: Distribution of case studies according to life cycle phase and spatial scale

\section{Occupant-centric building operation}

As stated in the introduction, occupant preferences for the indoor environment and their behavioral patterns are far more diverse than is commonly understood by practitioners. Additionally, occupancy and occupant behaviors might change over the life-cycle of a building (e.g., new tenants, transformation of building use) or due to events which have not been considered during design (e.g., heat waves, new noisy road close to a building). To address this, occupant-centric control (OCC) involves the sensing of actual indoor environmental quality, occupants' presence, and occupants' interactions with buildings and feeding this information directly back into control algorithms to achieve both high levels of energy efficiency and comfort, while maintaining usability and perceived control. While demand response-based controls have been slowly implemented for decades, modern OCC has the potential to more rapidly increase the impact on building performance due to recent advancements in available and affordable sensor, mobile and wearable devices, and the data processing technologies that can harness large data for control. In addition, modern building management systems (BMS) increasingly have the ability to interface with a wider array of data sources through web-based data exchange methods and efforts in standardization in point labelling. This section builds upon techniques discussed in previous sections with a focus on their transformations into the building control domain to improve occupant-centric building operation. Unlike conventional indoor climate control in which occupancy and occupant preferences are assumed or taken generically from a design code or standard, we define OCC as an approach for indoor climate control in which occupancy and/or occupants' comfort and preferences are directly measured or indirectly inferred from a variety of sensors, occupant feedback from control interfaces or mobile and wearable devices. This information is then used to train models to adapt to actual context-related conditions and occupants' needs. 


\subsection{State-of-the-art}

Section 3 outlined the emerging methods of occupancy data collection and modeling. Much of these data are used as inputs to the OCC process. In addition, OCC-specific methods are emerging for detecting presence or occupant counts with various sensors transform from cubicle or room-level to building-level. The most common sensor type used in practice for presence detection in building controls is the passive infrared or ultrasonic motion detector. While occupant count detection is still an on-going research challenge, the most promising current sensing approaches rely on people counting cameras at main entry points and WiFi or Bluetooth-enabled device counts [100-102]. $\mathrm{CO}_{2}$ concentration and electric lighting and plug-in equipment use are other promising commonly-available data types to gain some understanding of the occupancy levels without explicitly sensing the number of occupants $[103,104]$.

Numerous studies have localized presence detection to be directly used for lighting automation - e.g., vacancy off lighting [105-108]. However, considering the slow thermal response of buildings, a forecasting stage is also needed for HVAC controls. Hence, methods to learn from the past patterns of occupancy and to generate predictions based upon these patterns have been an active research area. In some case studies, the learning process was undertaken online in a controller whereby key occupancy metrics such as the earliest expected arrival or the latest expected departure times were estimated in realtime [e.g., 109]. In others, the learning process was offline; as such, the metrics were estimated from an archived dataset and used in controls $[110,111]$. The case studies documented in the reviewed literature have focused on the use of occupancy information for variable-air-volume (VAV) terminal units, perimeter heaters, and fan coil unit controls.

Besides detecting occupants in buildings, OCC systems should also be able to accurately infer what the users want so they can successfully modulate comfort control systems to improve occupant satisfaction. Subjective indoor comfort information can be collected either actively through asking occupants what they want or by passively observing behavior that indicates discomfort. Several new active methods are emerging through the use of mobile [112] and wearable applications [113] to crowd-source comfort feedback that can be used for control. New passive techniques are emerging from adaptive behaviors such as occupant interactions with the building interfaces, e.g., thermostats or light switches. Rather than controlling indoor air temperatures at constant and standard setpoints with the misconception to provide and maintain comfort for the majority of the occupants, parameters in addition to air temperature (e.g. mean radiant temperature) can be used to better infer occupant comfort. OCC relies on occupants' feedback with the intent to provide personalized comfort conditions in each thermal or lighting zone. The occupant feedback recorded at varying conditions is used to learn the preferred indoor conditions [114, 115]. For example, Peng, Nagy and Schlüter [116] and Gunay, O'Brien, Beausoleil-Morrison and Bursill [117] proposed methods to learn preferred indoor temperatures, which were used to adapt zone temperature setpoints. Similarly, Park, Dougherty, Fritz and Nagy [118] and Nagy, Yong, Frei and Schlueter [108] developed algorithms to learn preferred indoor illuminance levels, which were used to adapt illuminance setpoints for daylight-integrated lighting controls.

The aforementioned approach to detect occupants, learn or ask for their comfort feedback, and train models on their behavior is finding its way into practice due to modernized BMS infrastructure and its ability to synthesize data from many more sources. Aggregation of Internet of Things (IoT) data from disparate systems for the purpose of control can be enhanced through data connectivity and middle-ware platforms [119] and meta-data label standardization [74], see also Section 3.2. 


\subsection{Existing challenges}

Real world, true implementations of occupant-centric controls are rare. In fact, Park, Ouf, Gunay, Peng, O'Brien, Kjærgaard and Nagy [120] conducted a literature review and identified only about 42 case studies that would fit this label. The following is a list of findings of this review, identifying the challenges and limitations:

- The reviewed field implementations were small scale. The experiments often involved only a few occupants and lacked longevity or large sample sizes (e.g. months and fewer than ten participants). Given inter-occupant diversity and potential variations in behavioral patterns between seasons, small samples and short test periods may not be representative. Further, the experiments were conducted mainly by a few research groups, and as such they took place only in a few climatic conditions, and nearly $60 \%$ of them in academic buildings with a limited number of building system configurations. Given diversity in occupant behavior, variations across different building archetypes, climatic conditions, large-scale field implementations extended over multiple seasons in different climatic conditions are required for the assessment of OCC in real world implementations.

- Many of the existing implementations lack a rigorous performance measurement and verification procedure. Given the difficulty in conducting side-by-side experiments in identical rooms with similar occupancy patterns at the field-scale, researchers sometimes resorted to changing between two or more control algorithms every week in the same space [114, 121]. Further, as they often lacked access to lighting, heating, cooling submeters dedicated to investigated spaces, they resorted to other indicators to quantify energy savings - e.g., radiator operation time, volume of conditioned air delivered $[117,122,123]$ - or simulation $[121,124]$. To infer occupants' satisfaction with the occupant-centric control algorithms, only few studies analyzed whether any noticeable changes in occupants' adaptive behavior patterns or complaint frequencies were followed by their implementation $[106,117,123]$. In addition, there were considerable variations in the sensor, meter, and actuator configuration; and in some cases, details regarding the data infrastructure were missing or incomplete. These findings indicate the need for larger scale occupant-centric control implementations and guidelines detailing their configuration, implementation, and measurement and verification.

- Many of the case studies involved a learning algorithm to model occupancy patterns and occupant comfort preferences. The techniques used in occupant modeling remain fragmented in the reviewed studies and they are generally not ready for widespread application. For example, models to capture occupancy patterns were developed using following techniques: logistic regression [125]; decision trees and k-means clustering [126]; hidden Markov models [127]; and persistence-based forecasting of the occupancy profile [103]. Similarly, occupant comfort preference learning has been achieved using Fisher discriminant analysis [122]; fuzzy predictive modeling [123]; logistic regression [117, 121]; algebraic sum of comfort votes [124]; and others. Further, there were subtle differences in the assimilation of the occupant-related data in these models. For example, Gunay et al. [117, 121] updated learned user preferences (e.g., slightly de-/increasing heating/cooling setpoints) when there were no adaptive actions registered in an occupied space as well as when there were adaptive actions. In contrast, Nagy, Yong and Schlueter [106] updated learned user preferences for indoor illuminance only when there was a light switch-on event.

- Research to develop methods for incorporating learned comfort information from behavior patterns or comfort surveys to building automation systems remains anecdotal. Recognizing the technical limitations of many existing building automation systems, the question is: how can OCC algorithms be formulated without compromising the advantages of both manual control and automation [128]? 


\subsection{Research priorities}

In order to tackle the addressed challenges and open questions a thorough review of the scientific literature on real-world implementations of occupant-centric control algorithms has been conducted. This led to several research activities in order to find answers to the following research questions:

- What is the right balance between manual and automated controls? Especially, the use of OCC algorithms in buildings in which occupants have access to unmonitored manual control systems, such as operable windows, will be investigated. Further, the impact of the level of occupant control given through integrated control interfaces (e.g., $\pm 2^{\circ} \mathrm{C}$ override permission over a default temperature setpoint) needs to be examined with regard to energy and comfort performance of OCC.

- How does the design and configuration of control interfaces affect the performance of OCC algorithms? Answering this question coincides with the activity addressed in Section 2.3.3 and will require the investigation of both manual and automated control interfaces through controlled experiments. Specifically, it will be investigated what information should be displayed on interfaces and how occupancy and occupant preferences should be learned, updated, stored, and used.

- How can the energy and comfort impact of OCC algorithms be measured and verified? Appropriate sample size and testing period as well as methods to unobtrusively and reliably monitor and quantify comfort benefits of OCC will be studied.

- Which space and buildings types are suitable for the defined OCC categories? For example, some OCC categories may not be applicable for certain building types, because space use, available sensing technologies and HVAC system configurations could represent major constraints for certain OCC algorithms.

- Which emerging products and technologies can have an impact on the applicability of OCC in the future?

The associated research activities are as follows:

\subsubsection{Survey on common sensing technologies in building operation}

This international survey will reveal common occupant sensing technologies for energy management across different building types and in different countries; and, it will determine how these technologies are used and supplemented with operators' expertise. A questionnaire is being designed to determine the input data requirements for OCC algorithms and to prioritize certain building system configurations. It is intended to guide in-person or phone interviews with building operators, and facility and energy managers.

\subsubsection{Development of OCC simulation environment}

The objective of this activity is to develop a simulation environment for the development and assessment of OCC algorithms. This will be a sandbox environment for rapid preliminary testing of the OCC algorithms. For example, different configurational settings of OCCs (e.g. preference learning/forgetting rate, learning algorithms, temporary override periods, level of control offered to the occupants) can be investigated in simulation prior to their deployment in real life case studies. This simulation environment will be implemented in the building performance simulation tool EnergyPlus. The capabilities of this environment will be demonstrated through simulations with archetypical building energy models in different climatic conditions. 


\subsubsection{Implementing OCC in case studies}

A pressing research need is to conduct a number of well-documented systematic case studies to demonstrate the energy and comfort performance benefits of occupant-centric controls. The findings of these case studies need to be synthesized, and best practices for their implementation, measurement, and verification need to be documented for different building archetypes and climatic conditions.

As a first step, based on the literature review findings and discussions during the Annex 79 meetings, the seven broad OCC categories listed in Figure 8 were defined. The first three of these categories rely on presence sensing technologies to modify building-level on-off or zone-level temperature setback schedules for HVAC and to switch off electric lighting in vacant lighting zones. The categories four and five modulate the airflow rates of HVAC systems (e.g., AHUs and VAV terminal units) at the buildingand zone-level, respectively. The categories six and seven adapt the indoor temperature and illuminance setpoints during occupancy to preferred indoor climatic conditions. For each of the seven broad control categories, several experiments in different climatic conditions and building types will be carried out.

For the selection of case study buildings, a typology of descriptors will be developed for categorization and analysis of different buildings. Amongst others, these descriptors include space attributes, sensing, automation, and system attributes. Further, the activity entails the integration of occupant-centric control algorithms into the building automation systems of the case study buildings. Additionally, emerging indoor climate control technologies relevant to the use of OCC in buildings (e.g., personal comfort system chairs [129]) will be reviewed. Technical and non-technical obstacles emerging at this phase will be carefully documented for future reference.

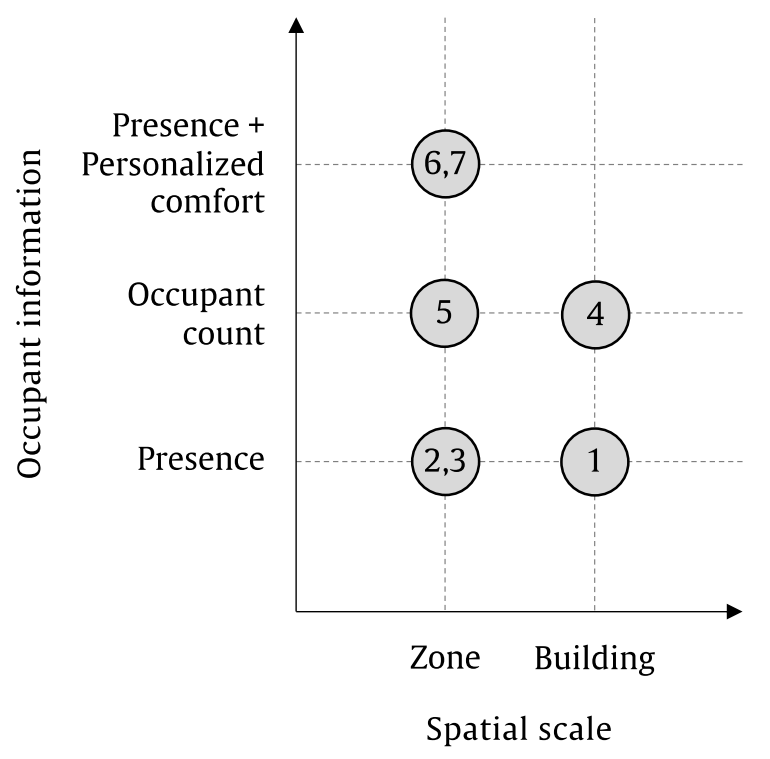

(1) Scheduling system-level equipment based on first arrival and last departure times in a building

(2) Applying zone temperature setback based on first and last arrival and last departure times

(3) Switching off lights based on vacancy detection

(4) Modulating minimum outdoor airflow setpoint based on system-level occupancy

(5) Modulating minimum airflow setpoint based on zone-level occupancy

(6) Adapting zone temperature setpoints based on learned temperature preferences

(7) Adapting illuminance setpoints based on learned illuminance preferences

Figure 8: Case study structure for occupant-centric control strategies.

\section{Conclusion}

Despite the fact that occupancy and occupant behavior can greatly influence building performance in all its facets - comfort, health, usability, functionality, energy - there is an obvious lack of knowledge, tools, guidelines, and standards for practitioners to design and operate buildings accordingly. Although there has been significant progress in scientific work over the past decade, for example, documented in the outcomes of IEA EBC Annex 66, open research questions remain, new methodological approaches and 
technologies appear, and, most importantly, the transition from research to practice has not been solved yet.

Consequently, work in this field is continued and a follow-up project, IEA EBC Annex 79 on "Occupantcentric Building Design and Operation”. With this paper, the four main areas of focus were presented with their most pressing challenges and a proposed set of activities to be conducted, based on a condensed overview of the state-of-the-art in literature and practice. The research needed to address the challenges is both fundamental and applied in nature - the latter due to the lack of occupant-centricity in current practice regarding design and operating strategies. This also underlines a necessary paradigm shift of relieving occupants from a purely passive role in the consideration of architects and planners to putting their needs and preferences into the foreground, resulting in a complex and dynamic bi-directional interaction between occupants and buildings.

In the first of the two more fundamental fields, systematic explanatory theories of people's perception and behavior in the built environments are sought. Currently, the majority of standards for the design of indoor environments only focus on single-domain influences (thermal, visual, olfactory, and aural comfort), resulting in isolated treatments of indoor environments' multiple quality criteria. However, in reality occupants face multi-domain environmental exposure and implications on occupants' satisfaction, behavior and the energy use in buildings are not yet understood. Moreover, there is a need for a systematic approach to buildings' control interfaces in order to support and improve buildings' energy efficiency through occupant behavior. Appropriate and user-friendly control opportunities via adequately designed and configured building envelope components and technical systems as well as corresponding effective human-building interfaces have to be provided. So far, not enough attention has been paid to their availability, visibility, intuitiveness, responsiveness, and effectiveness.

Secondly, data-driven modeling of occupant presence and behavior appears as a promising approach as the availability of various sensing technologies and data sources increases rapidly. Data mining and artificial intelligence may be used for developing new models or for generating new knowledge in the field. Further, new occupancy data collection methods including scalable data sources, such as mobile position through WiFi signals and social media data, can be applied and modified for occupant modeling purposes. A community platform to share open data and code for modeling occupant behavior and actions will help to increase transparency and reproducibility of science; this is supported by advancing privacy protection methods such as anonymization for preprocessing released data.

More applied research will address, on one hand, the sustainable implementation of simulation-aided occupant-centric building design approaches, including robust design and other probabilistic methods, optimization, and generative design. This involves recommendations for the revision of codes and standards with regard to occupant modeling, and guidelines for practitioners for choosing the right occupant behavior model for building simulation in the design process. A synthetic population model of building occupants will be tested as an alternative approach to occupant behavior modeling.

On the other hand, occupant-centricity also has to be an integral part of building operation and management. Consequently, occupant-centric control (OCC) strategies in order to detect occupants, learn about their comfort requirements, and train models on their behavior have to be implemented into building management systems. Research has to be conducted to find the right balance between manual and automated controls and on how the design and configuration of control interfaces affect the performance of OCC algorithms. Further, the suitability of different OCC strategies for the respective building use has to be investigated. 
For these two major building life-cycle stages - design and operation - focused case studies will implement and test the new models to test novel concepts for further research and ultimately to normalize the practice of occupant-centric design and operation.

While this introductory paper intends to give an overview of the field with regards to recent and current research activities - mainly connected with work in Annex 79- the interested reader can find much more detail through the literature reviews on specific topics that are part of this special issue. While Annex 79 is only beginning its second year (at the time of publication), a large group of researchers from different fields is rapidly addressing the gaps in knowledge. At the end of Annex 79, in 2023, we expect to provide a suite of reports on occupant-centric building design and operation to key stakeholders: scientists and academics, practitioners, industry, and policymakers. More information on Annex 79 can be found at http://annex79.iea-ebc.org.

\section{References}

[1] L.O. Degelman, A model for simulation of daylighting and occupancy sensors as an energy control strategy for office buildings, Proceedings of building simulation, 1999, pp. 571-578.

[2] P. Hoes, J.L.M. Hensen, M.G.L.C. Loomans, B. de Vries, D. Bourgeois, User behavior in whole building simulation, Energy and Buildings 41(3) (2009) 295-302.

[3] D. Yan, T. Hong, EBC Annex 66 Final Report - Definition and simulation of occupant behavior in buildings, 2018.

[4] S. Abbaszadeh, L. Zagreus, D. Lehrer, C. Huizenga, Occupant satisfaction with indoor environmental quality in green buildings, UC Berkeley, Center for Environmental Design Research, 2006.

[5] C. Huizenga, S. Abbaszadeh, L. Zagreus, E.A. Arens, Air quality and thermal comfort in office buildings: results of a large indoor environmental quality survey, (2006).

[6] G.R. Newsham, B.J. Birt, C. Arsenault, A.J.L. Thompson, J.A. Veitch, S. Mancini, A.D. Galasiu, B.N. Gover, I.A. Macdonald, G.J. Burns, Do 'green' buildings have better indoor environments? New evidence, Building Research \& Information 41(4) (2013) 415-434.

[7] Y.S. Lee, S.-K. Kim, Indoor environmental quality in LEED-certified buildings in the US, Journal of Asian Architecture and Building Engineering 7(2) (2008) 293-300.

[8] S. Altomonte, S. Schiavon, Occupant satisfaction in LEED and non-LEED certified buildings, Building and Environment 68(Supplement C) (2013) 66-76.

[9] M. Frontczak, S. Schiavon, J. Goins, E. Arens, H. Zhang, P. Wargocki, Quantitative relationships between occupant satisfaction and satisfaction aspects of indoor environmental quality and building design, Indoor Air 22(2) (2012) 119-131.

[10] T. Abuimara, W. O'Brien, B. Gunay, J. Day, H. Burpee, Designing for Occupants: A Review of the Integrated Design Practice, CEEE 2018 Summer Study on Energy Efficiency in Buildings, Pacific Grove, CA, 2018.

[11] T. Hong, D. Yan, S. D'Oca, C.-f. Chen, Ten questions concerning occupant behavior in buildings: The big picture, Building and Environment 114 (2017) 518-530.

[12] G. Brager, G. Paliaga, R. De Dear, Operable windows, personal control and occupant comfort, ASHRAE Transactions 110(2) (2004).

[13] J. Heerwagen, C. Diamond, Adaptations and coping: occupant response to discomfort in energy efficient buildings, Proceedings of ACEEE Summer School on Energy Efficiency in Buildings, Washington DC, 1992.

[14] J. Kim, S. Schiavon, G. Brager, Personal comfort models-A new paradigm in thermal comfort for occupant-centric environmental control, Building and Environment 132 (2018) 114-124.

[15] D. Li, C.C. Menassa, V.R. Kamat, Personalized human comfort in indoor building environments under diverse conditioning modes, Building and Environment 126 (2017) 304-317. 
[16] J. Kim, R. de Dear, Nonlinear relationships between individual IEQ factors and overall workspace satisfaction, Building and Environment 49 (2012) 33-40.

[17] H.B. Gunay, W. Shen, G. Newsham, A. Ashouri, Modelling and analysis of unsolicited temperature setpoint change requests in office buildings, Building and Environment 133 (2018) 203-212.

[18] S. Gilani, W. O'Brien, A preliminary study of occupants' use of manual lighting controls in private offices: A case study, Energy and Buildings 159 (2018) 572-586.

[19] C. Duarte, K. Van Den Wymelenberg, C. Rieger, Revealing occupancy patterns in an office building through the use of occupancy sensor data, Energy and Buildings 67 (2013) 587-595.

[20] S. D'Oca, T. Hong, Occupancy schedules learning process through a data mining framework, Energy and Buildings 88(0) (2015) 395-408.

[21] W. O'Brien, I. Gaetani, S. Gilani, S. Carlucci, P.-J. Hoes, J. Hensen, International survey on current occupant modelling approaches in building performance simulation, Journal of Building Performance Simulation (2016) 1-19.

[22] S. Gilani, W. O'Brien, H.B. Gunay, J.S. Carrizo, Use of dynamic occupant behavior models in the building design and code compliance processes, Energy and Buildings 117(1) (2016) 260-271.

[23] A. Mahdavi, M. Taheri, An ontology for building monitoring, Journal of Building Performance Simulation 10(5-6) (2017) 499-508.

[24] A. Wagner, W. O’Brien, B. Dong, Exploring Occupant Behavior in Buildings: Methods and Challenges, Springer2017.

[25] W. O'Brien, H.B. Gunay, F. Tahmasebi, A. Mahdavi, A preliminary study of representing the interoccupant diversity in occupant modelling, Journal of Building Performance Simulation 10(5-6) (2017) 509-526.

[26] A. Mahdavi, F. Tahmasebi, On the quality evaluation of behavioural models for building performance applications, Journal of Building Performance Simulation 10(5-6) (2017) 554-564.

[27] T. Hong, H. Sun, Y. Chen, S.C. Taylor-Lange, D. Yan, An occupant behavior modeling tool for cosimulation, Energy and Buildings 117 (2016) 272-281.

[28] H.B. Gunay, W. O'Brien, I. Beausoleil-Morrison, Implementation and comparison of existing occupant behaviour models in EnergyPlus, Journal of Building Performance Simulation (2015) 1-46. [29] I. Gaetani, P.-J. Hoes, J.L.M. Hensen, Occupant behavior in building energy simulation: Towards a fit-for-purpose modeling strategy, Energy and Buildings 121 (2016) 188-204.

[30] S. D’Oca, C.-F. Chen, T. Hong, Z. Belafi, Synthesizing building physics with social psychology: An interdisciplinary framework for context and occupant behavior in office buildings, Energy Research \& Social Science 34 (2017) 240-251.

[31] T. Hong, S. D'Oca, W.J.N. Turner, S.C. Taylor-Lange, An ontology to represent energy-related occupant behavior in buildings. Part I: Introduction to the DNAs framework, Building and Environment 92 (2015) 764-777.

[32] D. Yan, T. Hong, B. Dong, A. Mahdavi, S. D’Oca, I. Gaetani, X. Feng, IEA EBC Annex 66:

Definition and simulation of occupant behavior in buildings, Energy and Buildings 156 (2017) 258-270.

[33] D. Yan, W. O’Brien, T. Hong, X. Feng, H. Burak Gunay, F. Tahmasebi, A. Mahdavi, Occupant behavior modeling for building performance simulation: Current state and future challenges, Energy and Buildings 107 (2015) 264-278.

[34] Y.-C. Wu, A. Mahdavi, Assessment of thermal comfort under transitional conditions, Building and Environment 76 (2014) 30-36.

[35] M.A. Ortiz, S.R. Kurvers, P.M. Bluyssen, A review of comfort, health, and energy use:

Understanding daily energy use and wellbeing for the development of a new approach to study comfort, Energy and Buildings 152 (2017) 323-335.

[36] R.F. Rupp, N.G. Vásquez, R. Lamberts, A review of human thermal comfort in the built environment, Energy and Buildings 105 (2015) 178-205.

[37] M. Schweiker, G.M. Huebner, B.R. Kingma, R. Kramer, H. Pallubinsky, Drivers of diversity in human thermal perception-A review for holistic comfort models, Temperature 5(4) (2018) 308-342. 
[38] L. Edwards, P.A. Torcellini, A literature review of the effects of natural light on building occupants, National Renewable Energy Laboratory Golden, CO2002.

[39] A.D. Galasiu, J.A. Veitch, Occupant preferences and satisfaction with the luminous environment and control systems in daylit offices: a literature review, Energy and Buildings 38(7) (2006) 728-742.

[40] N.-G. Vardaxis, D. Bard, K. Persson Waye, Review of acoustic comfort evaluation in dwellingsPart I: Associations of acoustic field data to subjective responses from building surveys, Building Acoustics 25(2) (2018) 151-170.

[41] N.-G. Vardaxis, D. Bard, Review of acoustic comfort evaluation in dwellings: Part II-Impact sound data associated with subjective responses in laboratory tests, Building Acoustics 25(2) (2018) 171-192.

[42] S. Torresin, G. Pernigotto, F. Cappelletti, A. Gasparella, Combined effects of environmental factors on human perception and objective performance: A review of experimental laboratory works, Indoor air 28(4) (2018) 525-538.

[43] J.K. Day, W. O'Brien, Oh behave! Survey stories and lessons learned from building occupants in high-performance buildings, Energy Research \& Social Science 31 (2017) 11-20.

[44] T. Hong, S.C. Taylor-Lange, S. D’Oca, D. Yan, S.P. Corgnati, Advances in research and applications of energy-related occupant behavior in buildings, Energy and buildings 116 (2016) 694-702.

[45] M. Schweiker, S. Carlucci, R.K. Andersen, B. Dong, W. O’Brien, Occupancy and Occupants' Actions, Exploring Occupant Behavior in Buildings, Springer2018, pp. 7-38.

[46] A. Mahdavi, Can We Quantify the Ecological Valency of Built Environments?, Applied Mechanics and Materials, Trans Tech Publ, 2019, pp. 369-373.

[47] W. O'Brien, M. Schweiker, J.K. Day, Get the picture? Lessons learned from a smartphone-based post-occupancy evaluation, Energy Research \& Social Science 56 (2019) 101224.

[48] J. Day, L. Heschong, Understanding Behavior Potential: the Role of Building Interfaces Julia Day, Kansas State University, ACEEE Summer Study on Energy Efficiency in Buildings, Pacific Grove, CA, 2016.

[49] J. Day, A comprehensive review of human-building interfaces and occupant behavior, Building and Environment (Forthcoming).

[50] M. Schweiker, Review of multi - variable approaches to indoor environmental perception and behaviour, Building and Environment (Forthcoming).

[51] A. Heydarian, Review on psychological theories of perception and behaviour Building and Environment (Forthcoming).

[52] M. Schweiker, C. Moosmann, A. Wagner, Integrating Human Satisfaction into the Design PhaseGenerating Motivation and Knowledge in Architectural Education, REAL CORP 2019-IS THIS THE

REAL WORLD? Perfect Smart Cities vs. Real Emotional Cities. Proceedings of 24th International Conference on Urban Planning, Regional Development and Information Society, CORP-Compentence Center of Urban and Regional Planning, 2019, pp. 443-452.

[53] A. Mahdavi, Human agents in building modelling: between Déjà Vu and Epiphany Proceedings of BauSIM2018, Karlsruhe, Germany, 2018.

[54] A. Mahdavi, C. Berger, An inquiry into the certification potential of built environments' affordance, E3S Web of Conferences, EDP Sciences, 2019.

[55] J. Varjo, V. Hongisto, A. Haapakangas, H. Maula, H. Koskela, J. Hyönä, Simultaneous effects of irrelevant speech, temperature and ventilation rate on performance and satisfaction in open-plan offices, Journal of Environmental Psychology 44 (2015) 16-33.

[56] L. Huang, Y. Zhu, Q. Ouyang, B. Cao, A study on the effects of thermal, luminous, and acoustic environments on indoor environmental comfort in offices, Building and Environment 49 (2012) 304-309. [57] D. Tiller, L.M. Wang, A. Musser, M. Radik, AB-10-017: Combined effects of noise and temperature on human comfort and performance (1128-RP), (2010).

[58] H. Knötig, Some essentials of the Vienna school of human ecology, Archivum Oecologiae Hominis 1992. 
[59] A. Mahdavi, H. Teufl, C. Berger, Application of the ecological valency concept to buildings' environmental control systems, IOP Conference Series: Materials Science and Engineering, IOP Publishing, 2019, p. 042022.

[60] H.-W. Lin, T. Hong, On variations of space-heating energy use in office buildings, Applied Energy $111(2013)$ 515-528.

[61] X. Luo, K.P. Lam, Y. Chen, T. Hong, Performance evaluation of an agent-based occupancy simulation model, Building and Environment 115 (2017) 42-53.

[62] Y.S. Lee, A.M. Malkawi, Simulating multiple occupant behaviors in buildings: An agent-based modeling approach, Energy and Buildings 69 (2014) 407-416.

[63] B. Dong, V. Prakash, F. Feng, Z. O'Neill, A review of smart building sensing system for better indoor environment control, Energy and Buildings (2019).

[64] M.B. Kjærgaard, F.C. Sangogboye, Categorization framework and survey of occupancy sensing systems, Pervasive and Mobile Computing 38 (2017) 1-13.

[65] C. de Bakker, M. Aries, H. Kort, A. Rosemann, Occupancy-based lighting control in open-plan office spaces: A state-of-the-art review, Building and Environment 112 (2017) 308-321.

[66] W. Wang, J. Chen, T. Hong, N. Zhu, Occupancy prediction through Markov based feedback recurrent neural network (M-FRNN) algorithm with WiFi probe technology, Building and Environment 138 (2018) 160-170.

[67] F.C. Sangogboye, M.B. Kjærgaard, Scalable and Accurate Estimation of Room-Level People Counts from Multi-Modal Fusion of Perimeter Sensors and WiFi Trajectories, 2019 20th IEEE International Conference on Mobile Data Management (MDM), IEEE, 2019, pp. 37-42.

[68] I.H. Witten, E. Frank, M.A. Hall, C.J. Pal, Data Mining: Practical machine learning tools and techniques, Morgan Kaufmann2016.

[69] F.C. Sangogboye, M.B. Kjærgaard, PROMT: predicting occupancy presence in multiple resolution with time-shift agnostic classification, Computer Science-Research and Development 33(1-2) (2018) 105115.

[70] A. Mirakhorli, B. Dong, Occupancy behavior based model predictive control for building indoor climate-A critical review, Energy and Buildings 129 (2016) 499-513.

[71] G. Serale, M. Fiorentini, A. Capozzoli, D. Bernardini, A. Bemporad, Model predictive control (MPC) for enhancing building and HVAC system energy efficiency: Problem formulation, applications and opportunities, Energies 11(3) (2018) 631.

[72] M.G. Wollsen, M.B. Kjærgaard, B.N. Jørgensen, Influential factors for accurate load prediction in a demand response context, 2016 IEEE Conference on Technologies for Sustainability (SusTech), IEEE, 2016, pp. 9-13.

[73] S. Pfenninger, J. DeCarolis, L. Hirth, S. Quoilin, I. Staffell, The importance of open data and software: Is energy research lagging behind?, Energy Policy 101 (2017) 211-215.

[74] B. Balaji, A. Bhattacharya, G. Fierro, J. Gao, J. Gluck, D. Hong, A. Johansen, J. Koh, J. Ploennigs, Y. Agarwal, Brick: Towards a unified metadata schema for buildings, Proceedings of the 3rd ACM International Conference on Systems for Energy-Efficient Built Environments, ACM, 2016, pp. 41-50. [75] R. Jia, F.C. Sangogboye, T. Hong, C. Spanos, M.B. Kjærgaard, PAD: protecting anonymity in publishing building related datasets, Proceedings of the 4th ACM International Conference on Systems for Energy-Efficient Built Environments, ACM, 2017, p. 4.

[76] B. Dong, W. Wenbo, W. Ryan, A. Sadam, P. Vishnu, Derive Urban Scale Occupant Behavior Profiles From Mobile Position Data, Building Simulation, Rome, Italy, 2019.

[77] Q. Wang, J.E. Taylor, Process map for urban-human mobility and civil infrastructure data collection using geosocial networking platforms, Journal of Computing in Civil Engineering 30(2) (2015) 04015004 .

[78] N.E. Phillips, B.L. Levy, R.J. Sampson, M.L. Small, R.Q. Wang, The Social Integration of American Cities: Network Measures of Connectedness Based on Everyday Mobility Across Neighborhoods, Sociological Methods \& Research (2019) 0049124119852386. 
[79] ANSI/ASHRAE/IES, Standard 90.1: Energy Standard for Buildings Except Low-Rise Residential Buildings, Atlanta, 2016.

[80] D. Denyer, D. Tranfield, J.E. van Aken, Developing Design Propositions through Research Synthesis, Organization Studies 29(3) (2008) 393-413.

[81] M. Aria, C. Cuccurullo, bibliometrix: An R-tool for comprehensive science mapping analysis, Journal of Informetrics 11(4) (2017) 959-975.

[82] N.J. van Eck, L. Waltman, Software survey: VOSviewer, a computer program for bibliometric mapping, Scientometrics 84(2) (2010) 523-538.

[83] J.H. Schwee, F.C. Sangogboye, M.B. Kjærgaard, Evaluating Practical Privacy Attacks for Building Data Anonymized by Standard Methods, International Workshop on Security and Privacy for the Internetof-Things, 2019.

[84] H.B. Gunay, W. O'Brien, I. Beausoleil-Morrison, Implementation and comparison of existing occupant behaviour models in EnergyPlus, Journal of Building Performance Simulation 9(6) (2016) 567588.

[85] W. O'Brien, H.B. Gunay, The contextual factors contributing to occupants' adaptive comfort behaviors in offices-A review and proposed modeling framework, Building and Environment 77 (2014) 77-87.

[86] F. Tahmasebi, A. Mahdavi, On the utility of occupants' behavioural diversity information for building performance simulation: An exploratory case study, Energy and Buildings 176 (2018) 380-389.

[87] F. Tahmasebi, W. O’Brien, Y. Wang, S. Stamp, D. Mumovic, A. Mahdavi, Inter-Occupant Diversity in Occupant Behaviour Models: Exploring Potential Benefits for Predicting Light Switch-on Actions, Building Simulation, Rome, Italy, 2019.

[88] E. Azar, Simulation-aided occupant-centric building design: A critical review of tools, methods, and applications Building and Environment, Building and Environment (Forthcoming).

[89] M. Ouf, W. O'Brien, H.B. Gunay, Optimization of electricity use in office buildings under occupant uncertainty Journal of Building Performance Simulation (in press).

[90] T. Abuimara, W. O'Brien, B. Gunay, J.S. Carrizo, Towards occupant-centric simulation-aided building design: a case study, Building Research \& Information 47(8) (2019) 866-882.

[91] W. O'Brien, An international review of occupant-related aspects of building energy codes and standards, Building and Environment (forthcoming).

[92] D. Kim, Y. Kim, S. Lee, W. Park, Y. Bok, S. Ha, S. Lee, Development of Reference Building

Energy Models for South Korea, Proc. of the 15th IBPSA Conf, 2017, pp. 2693-2700.

[93] C. Wang, D. Yan, Y. Jiang, A novel approach for building occupancy simulation, Building simulation, Springer, 2011, pp. 149-167.

[94] R. Stewart, M. Urban, S. Duchscherer, J. Kaufman, A. Morton, G. Thakur, J. Piburn, J. Moehl, A Bayesian machine learning model for estimating building occupancy from open source data, Natural Hazards 81(3) (2016) 1929-1956.

[95] A. Majid, L. Chen, G. Chen, H.T. Mirza, I. Hussain, J. Woodward, A context-aware personalized travel recommendation system based on geotagged social media data mining, International Journal of Geographical Information Science 27(4) (2013) 662-684.

[96] C. Yang, M. Xiao, X. Ding, W. Tian, Y. Zhai, J. Chen, L. Liu, X. Ye, Exploring human mobility patterns using geo-tagged social media data at the group level, Journal of Spatial Science 64(2) (2019) 221-238.

[97] D. Pohl, A. Bouchachia, H. Hellwagner, Batch-based active learning: Application to social media data for crisis management, Expert Systems with Applications 93 (2018) 232-244.

[98] V.F. Ličina, T. Cheung, H. Zhang, R. De Dear, T. Parkinson, E. Arens, C. Chun, S. Schiavon, M. Luo, G. Brager, Development of the ASHRAE global thermal comfort database II, Building and Environment 142 (2018) 502-512.

[99] S. D'Oca, S. Corgnati, A.L. Pisello, T. Hong, Introduction to an occupant behavior motivation survey framework, (2016). 
[100] B. Balaji, J. Xu, A. Nwokafor, R. Gupta, Y. Agarwal, Sentinel: occupancy based HVAC actuation using existing WiFi infrastructure within commercial buildings, Proceedings of the 11th ACM

Conference on Embedded Networked Sensor Systems, Association for Computing Machinery, 2013, p.

17.

[101] Z. Wang, T. Hong, M.A. Piette, M. Pritoni, Inferring occupant counts from Wi-Fi data in buildings through machine learning, Building and Environment (2019).

[102] J.Y. Park, T. Dougherty, Z. Nagy, A Bluetooth based occupancy detection for buildings, SimBuild, ASHRAE BPACS/IBPSA-USA, Chicago, 2018.

[103] R. De Coninck, L. Helsen, Practical implementation and evaluation of model predictive control for an office building in Brussels, Energy and Buildings 111 (2016) 290-298.

[104] B.W. Hobson, D. Lowcay, H.B. Gunay, A. Ashouri, G.R. Newsham, Opportunistic occupancycount estimation using sensor fusion: A case study, Building and Environment (2019).

[105] V. Garg, N.K. Bansal, Smart occupancy sensors to reduce energy consumption, Energy and Buildings 32(1) (2000) 81-87.

[106] Z. Nagy, F.Y. Yong, A. Schlueter, Occupant centered lighting control: a user study on balancing comfort, acceptance, and energy consumption, Energy and Buildings 126 (2016) 310-322.

[107] D. Maniccia, A. Tweed, A. Bierman, B. Von Neida, The effects of changing occupancy sensor time-out setting on energy savings, lamp cycling and maintenance costs, Journal of the Illuminating Engineering Society 30(2) (2001) 97-110.

[108] Z. Nagy, F.Y. Yong, M. Frei, A. Schlueter, Occupant centered lighting control for comfort and energy efficient building operation, Energy and Buildings 94 (2015) 100-108.

[109] H.B. Gunay, W. O'Brien, I. Beausoleil-Morrison, Development of an occupancy learning algorithm for terminal heating and cooling units, Building and Environment 93 (2015) 71-85.

[110] Y.-J. Wen, A. Agogino, Control of wireless-networked lighting in open-plan offices, Lighting Research \& Technology 43(2) (2011) 235-248.

[111] Y.-J. Wen, A.M. Agogino, Wireless networked lighting systems for optimizing energy savings and user satisfaction, 2008 IEEE Wireless Hive Networks Conference, IEEE, 2008, pp. 1-7.

[112] T. Sood, M. Quintana, P. Jayathissa, M. AbdelRahman, C. Miller, The SDE4 Learning Trail:

Crowdsourcing occupant comfort feedback at a net-zero energy building, (2019).

[113] P. Jayathissa, M. Quintana, T. Sood, N. Narzarian, C. Miller, Is your clock-face cozie? A

smartwatch methodology for the in-situ collection of occupant comfort data.

[114] A. Guillemin, N. Morel, Experimental results of a self-adaptive integrated control system in buildings: a pilot study, Solar Energy 72(5) (2002) 397-403.

[115] S. Lee, J. Joe, P. Karava, I. Bilionis, A. Tzempelikos, Implementation of a self-tuned HVAC controller to satisfy occupant thermal preferences and optimize energy use, Energy and Buildings 194 (2019) 301-316.

[116] Y. Peng, Z. Nagy, A. Schlüter, Temperature-preference learning with neural networks for occupantcentric building indoor climate controls, Building and Environment (2019).

[117] H.B. Gunay, W. O'Brien, I. Beausoleil-Morrison, J. Bursill, Development and implementation of a thermostat learning algorithm, Science and Technology for the Built Environment 24(1) (2018) 43-56.

[118] J.Y. Park, T. Dougherty, H. Fritz, Z. Nagy, LightLearn: An adaptive and occupant centered controller for lighting based on reinforcement learning, Building and Environment 147 (2019) 397-414.

[119] B. Kalluri, C. Miller, B. Seshadri, A. Schlueter, A cyber-physical middleware platform for buildings in smart cities, Advances in Informatics and Computing in Civil and Construction Engineering, Springer2019, pp. 645-652.

[120] J.Y. Park, M.M. Ouf, B. Gunay, Y. Peng, W. O'Brien, M.B. Kjærgaard, Z. Nagy, A critical review of field implementations of occupant-centric building controls, Building and Environment 165 (2019) 106351.

[121] H.B. Gunay, W. O'Brien, I. Beausoleil-Morrison, S. Gilani, Development and implementation of an adaptive lighting and blinds control algorithm, Building and Environment 113 (2017) 185-199. 
[122] M. Feldmeier, J.A. Paradiso, Personalized HVAC Control System, Internet of Things, IEEE, Tokyo, Japan, 2010.

[123] F. Jazizadeh, A. Ghahramani, B. Becerik-Gerber, T. Kichkaylo, M. Orosz, User-led decentralized thermal comfort driven HVAC operations for improved efficiency in office buildings, Energy and Buildings 70 (2014) 398-410.

[124] S. Purdon, B. Kusy, R. Jurdak, G. Challen, Model-free HVAC control using occupant feedback, IEEE International Workshop on Global Trends in Smart Cities, IEEE, 2013.

[125] S.H. Kim, H.J. Moon, Case study of an advanced integrated comfort control algorithm with cooling, ventilation, and humidification systems based on occupancy status, Building and Environment 133 (2018) 246-264.

[126] Y. Peng, A. Rysanek, Z. Nagy, A. Schlüter, Using machine learning techniques for occupancyprediction-based cooling control in office buildings, Applied Energy 211 (2018) 1343-1358.

[127] B. Dong, K.P. Lam, A real-time model predictive control for building heating and cooling systems based on the occupancy behavior pattern detection and local weather forecasting, Building Simulation 7 (2014) 89-106.

[128] S. Karjalainen, Should it be automatic or manual-the occupant's perspective on the design of domestic control systems, Energy and Buildings 65(October) (2013) 119-126.

[129] W. Pasut, H. Zhang, E. Arens, Y. Zhai, Energy-efficient comfort with a heated/cooled chair: Results from human subject tests, Building and Environment 84 (2015) 10-21. 